\title{
CONDENSATION CHARACTERISTICS DURING SUPERSONIC FLOW OF ORGANIC VAPOURS
}

\author{
N.H. MAHMOUD \\ Department of Mechanical Power Engineering, \\ Menoufiya University, Shebin El-Kom, EGYPT.
}

\section{ABSTRACT:}

Condensation of some organic vapours including ammonia, ethanol and freon-11 by homogeneous nucleation of liquid droplets has been studied here during supersonic flow through convergent-divergent nozzles. Theoretical model of the present work is based upon three groups of equations namely: gasdynamic equations, equations of condensation kinetics and droplets growth equations. Modified equations for the classical nucleation rate, droplets surface tension and the thermodynamic properties of the condensing vapour are used in the present theoretical model. Generally, present model predictions show that condensation characteristics of the tested organic vapours are qualitatively similar to those of steam condensation. Also, the present study indicates that the condensation characteristics of the tested organic vapours are affected with the operating parameters such as the vapour temperature and its mass fraction. The theoretical predictions of the pressure variation along the divergent sections of such supersonic nozzles are in good agreement with the published experimental measurements of these organic vapours.

KEYWORDS: Organic vapour, condensation, nucleation, supersonic flow, convergent-divergent nozzle, droplet growth.

\section{INTRODUCTION:}

Condensation of organic varpours by homogeneous nucleation has recently received a considerable attention due to its utilization in aeronautics, cloud physics, refrigeration technology, chemical industries and other areas. The basis of the classical theory of homogeneous condensation in vapours was developed by Farkas [1]. He showed that the condensation process in a vapour is the result of simultaneous reactions in which a cluster containing (n) molecules either gains or loses a molecule through molecular 


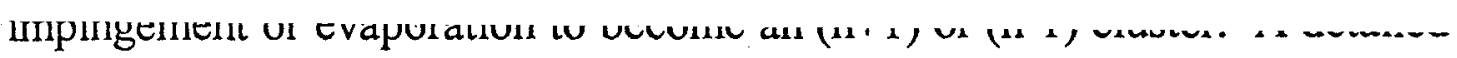

treatment was carried out by many investigators results in correlating the socalled the "classical nucleation rate" (which means the number of supercritical-sized droplets produced per unit mass of vapour per unit time). These basics were widely accepted owing to the verification by the cloud chamber measurements which were carried out by Volmer and Flood for water vapour and several organic fluids [2]. This theory was revised by many investigators in order to combine between the measured values of the nucleation rate and the predicted ones. Barschdorff and others [3] have reported that the final correction for the classical theory of condensation which was introduced by Feder and co-workers [4] gives the highly precise agreement between the theory and the measurements.

Isentropic expansion of varpours into the nucleation region may also be obtained within supersonic nozzles. Therefore, the supersonic nozzle experiment is highly accepted in studying homogeneous nucleation rate $[5,6]$ and droplet size [6] in water vapour expansion. Furthermore, the nozzle experiment technique was used to study the homogeneous nucleation processes in vapours other than water vapour such as ammonia [7], carbon dioxide [8] and other organic varpours like benzene and chloroform [9]. These researches were directed to detect the point of condensation incidence within the flow using pressure distribution measurements at discrete locations.

Models of predicting nucleating and condensing flows in nozzles are based on presenting three groups of equations. The first group correlates the nucleation rate, the second one concerns with describing the droplets growth and the third one estimates the gas dynamic characteristics of the condensing flow. These models result in pronounced success in predicting nucleating and condensing flow in nozzles [10-12] and show a notable success when they extended to be used in predicting the performance of wet steam turbines [13-14]. Some uncertainties in these models have been listed by many investigators [15-16]. These uncertainties include the effects of condensation coefficient, growth laws, nucleation rate, surface tension, thermodynamic characteristics and equation of the state on the accuracy of these models. Many researches have been carried out to solve the problems associated with these uncertainties. For example, the non-isothermal effects on the nucleation rate are modified using a factor introduced by Kantrowitz [17] into the basic formulation of the classical theory. This modified nucleation rate was coupled by Young [18] with modified droplet growth equations for both free-molecular and continuum flow regimes. Young's model [18] was found to be highly efficient computationally.

Basics of illustrating the above models for analyzing condensation characteristics of wet steam flow in nozzles were considered also in 
presenting similar models concern with predicting homogeneous nucleation and condensation of organic vapours during supersonic expansion in nozzles [19-20]. General results from nozzle experiments indicate that, with the exception of little organic vapours, all the vapours seem to obey the assumptions of the classical nucleation theory. Non-classical nucleation behavior (i.e., higher nucleation rates) was discovered by Jaeger et al. [7] in benzene, chloroform, freon- 11 and ammonia condensation. In order to release this discrepancy between theoretical predictions and measurements, modification factors such as "the factor $\Gamma$ " which was suggested by Wegener et al. [19] are introduced into the equation of nucleation rate. Wegener et al. [19] showed that the factor $\Gamma$ must be taken within $10^{3}<\Gamma$ $<10^{6}$ depending on the experimental conditions to combine between theory and measurements in detecting the onset of condensation for ethanol a as shown by Figure 7 in [19]\}. Therefore, the main purpose of the present work is to investigate the effects of some corrections which were suggested on the homogeneous nucleation theory upon the condensation characteristics during organic vapours expansion through supersonic nozzles. Besides, effects of some operating parameters such as initial value of vapour temperature and its mass fraction on the condensation behavior are also investigated here. The tested organic vapours in this work are ammonia $\left(\mathrm{NH}_{3}\right)$, ethanol $\left(\mathrm{C}_{2} \mathrm{H}_{5} \mathrm{OH}\right)$ and trichloromonofluoromethane or freon-11 $\left(\mathrm{CC}_{3} \mathrm{~F}\right)$.

\section{THEORETICAL MODELING OF THE GOVERNING}

\section{EQUATIONS:}

The present theoretical modeling is illustrated under the following assumptions:

a- The flow is one-dimensional, frictionless, without velocity slip and steady.

b- Organic substances of small mass fraction are mixed with dry air as carrier gas.

c- Condensation of organic vapours can happen in the divergent section of the tested nozzle after the occurrence of the supersaturation state .

d- Condensed phase consists of mono-dispersed, incompressible and spherical liquid droplets.

e- Coagulation between droplets is negligible.

Theoretical model of the present work is divided into three groups of equations namely: gasdynamic equations, equations of condensation kinetics and droplet growth equations. 
The gasdynamic equations simulate a multiphase flow of air-vapour and condensed droplets mixture through a nozzle are based upon the equation of state which takes the form

$$
P=\frac{\rho_{m} \cdot R_{g} \cdot T_{g}}{M}
$$

where $\mathrm{R}_{\mathrm{g}}$ is the molecular gas constant and $\mathrm{M}$ is the molecular weight. Properties for the mixture of vapour and air is correlated in the following equation

$$
\frac{1}{M}=\frac{1-\mu}{1-G} \cdot \frac{1}{M_{a}}+\frac{\mu-G}{1-G} \cdot \frac{1}{M_{g}}
$$

where $\mu$ is the mass fraction of the vapour and condensate in the two phase flow and $G$ is the mass fraction of the condensate and is defined as the condensate mass per unit mass of the gas-condensate mixture.

Now, the following definitions are considered. The mass fraction of the organic vapour in the mixture is defined by

$$
\mu=\frac{m_{g}}{m_{t}}=\frac{m_{g}}{m_{a}+m_{g}}
$$

The initial mass fraction of the vapour and condensate at nozzle entrance is given as

$$
\mu_{o}=\frac{m_{g o}}{m_{t}}=\frac{m_{g}+m_{f}}{m_{t}}=\text { cnost }
$$

But the mass fraction of air (i.e., inert carrier gas) is given by

$$
1-\mu_{o}=\frac{m_{a}}{m_{t}}
$$

Finally, the mass fraction of the condensate is expressed as

$$
G=\frac{m_{f}}{m_{l}}
$$

The total density of the gas-condensate mixture $\rho_{t}$ is expressed from the mass balance of steady flow as

$$
\begin{aligned}
& \mathrm{Q} m_{t}=m_{m}+m_{f}=m_{a}+m_{g}+m_{f}=\text { cons } \tan t \\
& \therefore \rho_{t}=\rho_{m}+\rho_{f}^{\prime}=\rho_{a}+\rho_{g}+\rho_{f}^{\prime}
\end{aligned}
$$

where $\rho_{f}^{\prime}$ is the density of condensate referred to the volume of the gaseous phase.

Depending on the definition of the mass fraction of condensate, the following is obtained 
and

$$
\left.\begin{array}{l}
\rho_{f}=G \cdot \rho_{t} \\
\rho_{t}=\frac{\rho_{m}}{1-G}
\end{array}\right\}
$$

Now; equations of conservation of mass, momentum and energy are given as

$$
\begin{aligned}
& \frac{\rho_{m} \cdot C \cdot A}{1-G}=\text { cons } \tan t=\dot{m} \\
& ,-A \cdot d P=\dot{m} \cdot d C \\
& d\left[\frac{\rho_{t} C^{2}}{2}+\overline{h_{l}}\right]=0
\end{aligned}
$$

and

where $\bar{h}_{t}$ is the average enthalpy of air-vapour and condensate mixture per unit volume and is given by

$$
\bar{h}_{t}=\rho_{a} \cdot h_{a}+\rho_{g} \cdot h_{g}+\rho_{f}^{\prime} \cdot h_{f}
$$

Therefore, Eq. (11) for energy conservation can given by

$$
d\left[\frac{\rho \cdot C^{2}}{2}+\rho_{a} \cdot h_{a}+\rho_{g} \cdot h_{g}+\rho_{f}^{\prime} \cdot h_{f}\right]=0
$$

This expression for energy equation can be rewritten for a mass $m_{t}$ of moving mixture to obtain

$$
d\left[\frac{m_{l} C^{2}}{2}+m_{a} \cdot h_{a}+m_{g} \cdot h_{g}+m_{f} \cdot h_{f}\right]=0
$$

When the vapour and condensate enthalpies are expressed with the aid of their temperature difference $\left(T_{g}-T_{f}\right)$ and the heat of phase transition to become

$$
h_{g}-h_{f}=h_{f g}+c_{f} \cdot\left(T_{g}-T_{f}\right)
$$

Considering the assumption that the enthalpy difference between the vapour and condensate phases (i.e., $h_{g}-h_{f}$ ) equals the heat of phase transition leads to modify the energy equation to

$$
d\left[\frac{m_{t} C^{2}}{2}+m_{a} \cdot h_{a}+m_{g} \cdot h_{g}+m_{f} \cdot\left(h_{g}-h_{j g}\right)\right]=0
$$

Consequently, Eq. (15) after multiplying by $\left(1 / \mathrm{m}_{\mathrm{t}}\right)$ gives

$$
d\left[\frac{C^{2}}{2}+\frac{m_{a}}{m_{t}} \cdot h_{a}+\frac{m_{g}}{m_{t}} \cdot h_{g}+\frac{m_{f}}{m_{t}} \cdot\left(h_{g}-h_{f g}\right)\right]=0
$$

Rearranging Eq. (16) yields to

$$
d\left[\frac{C^{2}}{2}+\frac{m_{a}}{m_{t}} \cdot h_{a}+\frac{m_{g}+m_{f}}{m_{t}} \cdot h_{g}-\frac{m_{f}}{m_{t}} \cdot h_{f g}\right]=0
$$

Inserting definitions of $\mu_{o}$ and $\mathrm{G}$ into Eq. (17) yields to

$$
d\left[\frac{C^{2}}{2}+\left(1-\mu_{t_{0}}\right) \cdot h_{a}+\mu_{0}, h_{g}-G \cdot h_{f k}\right]=0
$$


When supersaturation conditions prevail within a vapour during its expansion through a nozzle, a number of droplets of the critical size are formed per unit time in the unit mass or unit volume of the vapour. The critical radius of a droplet in equilibrium with its vapour is given in all textbooks concerning with the problems of nucleation and condensation $[16,21]$ as

$$
r_{c r}=\frac{2 \sigma}{\rho_{f} R_{g} T_{g} \ln (S)}=\frac{2 \sigma T_{s}}{\rho_{f} \cdot h_{f g} \cdot \Delta T}
$$

While the rate of nucleated critical droplets of radius $r_{\text {cr }}$ per unit volume is correlated on the basis of classical theory as a function of the local vapour conditions and under thermal equilibrium droplet growth to be

$$
J_{c l}=\left(\frac{2 \sigma}{\pi m^{3}}\right)^{1 / 2} \cdot \frac{\rho_{g}^{2}}{\rho_{f}} \exp \left(-\frac{\Delta G_{c r}}{k T_{g}}\right)
$$

where $\rho_{\mathrm{g}}$ is obtained as a function of $\mathrm{T}_{\mathrm{g}}, \mathrm{m}$ is the mass of a molecule and $\mathrm{k}$ is the Boltzmann's constant.

In the equation of classical nucleation rate (i.e., Eq.20.a), $\Delta \mathrm{G}_{\mathrm{cr}}$ is the critical free energy barrier during formation of a critical-size droplet and obtained from

$$
\Delta G_{c r}=\frac{4}{3} \pi r_{c r}^{2} \cdot \sigma
$$

Nucleation rate calculated from Eqs. (20) does not agree particularly well with condensation measurements in wet steam or organic vapours. Kantrovitz [17] discussed the disagreement between theoretical values of $\mathrm{J}_{\mathrm{cl}}$ and measured ones of steam and show that the droplet temperature does not remain constant during nucleation due to the release of latent heat. $\mathrm{He}$ derived a " non-isothermal" correction factor which is formulated by Young [22] as

$$
J_{t t}=\frac{1}{1+\Phi} \cdot J_{c t}
$$

where

$$
\Phi=2\left(\frac{\gamma-1}{\gamma+1}\right) \cdot\left(\frac{h_{f g}}{R_{g} T_{g}}\right) \cdot\left(\frac{h_{f g}}{R_{g} T_{g}}-\frac{1}{2}\right)
$$

The problem of disagreement between theoretical values of $\mathrm{J}_{\mathrm{cl}}$ and measured ones of organic vapours was discussed by Wegener, et al.[19] and $\mathrm{Wu}[20]$. They showed that the correct nucleation rate is calculated from

$$
J=\Gamma . J_{c l}
$$

where $\Gamma$ is a numerical coefficient formulated empirically to become a function on some of the critical parameters of droplets formation in water vapour and various organic vapours $[19,20]$. 
Now, the present work suggests a new formula for the nucleation rate "combines both approaches in Eqs. (21.a) and (21.b) to obtain

$$
J=\beta . J_{c l}
$$

where

$$
\beta=\Gamma \cdot \frac{1}{1+\Phi}
$$

\subsection{Droplets Growth:}

Due to the small fraction of the condensing vapour within the carrier airvapour mixture, the droplets remain small compared to the mean free path of the gaseous mixture. Therefore, the behavior of droplets growth is described here by free-molecular growth laws [20]. The rate at which a droplet grows in a free molecular environment is defined as the difference between the mass rate of molecules striking the droplet and adhering to its surface and the mass rate of molecules evaporating from the droplet surface. Consequently, the net rate of droplet growth can be expressed in many references $[19,23]$ as

$$
\frac{d r}{d t}=q_{c} \cdot \frac{M_{f}}{\rho_{f}} \cdot D_{c}\left(P_{g}, T_{g}\right)
$$

Mass condensation coefficient $q_{c}$ is defined by

$$
q_{c}=a_{t h} \cdot\left[1-\frac{D_{e}\left(T_{r}, r\right)}{D_{c}\left(P_{g}, T_{g}\right)}\right]
$$

where $T_{r}$ is the temperature on the surface of a droplet of radius $\mathrm{r}$ and $P_{r}$ is the saturated vapour pressure over a droplet surface of the radius $r$. In the above two expressions, $\mathrm{D}_{\mathrm{c}}\left(\mathrm{P}_{\mathrm{g}}, \mathrm{T}_{\mathrm{g}}\right)$ and $\mathrm{D}_{\mathrm{e}}\left(\mathrm{T}_{\mathrm{r}}, \mathrm{r}\right)$ are the impingement and evaporation rates which are defined on the basis of kinetic theory by

$$
\begin{gathered}
D_{c}\left(P_{g}, T_{g}\right)=P\left(T_{g}\right) \cdot\left(2 \pi M_{f} k T_{g}\right)^{-1 / 2} \\
, D_{c}\left(T_{r}, r\right)=P_{r}\left(T_{r}\right) \cdot\left[2 \pi M_{f} k T_{r}\right]^{-1 / 2}
\end{gathered}
$$

In order to obtain the droplet temperature, an energy balance upon the droplet surface is given below due to Hill [15] and Wegener, et al. [19] as

$$
\begin{aligned}
& \frac{a_{t h} \cdot \varepsilon_{g} \cdot k}{M_{f}}\left(D_{c} \cdot T_{g}-D_{c} \cdot T_{r}\right)+\frac{\left(1-a_{t h}\right) \cdot \varepsilon_{g} \cdot k \zeta_{g} \cdot D_{c}}{M_{f}} \cdot\left(T_{g}-T_{r}\right)+ \\
& \frac{\varepsilon_{c} \cdot k \cdot \zeta_{a} \cdot D_{a}}{M_{u}} \cdot\left(T_{g}-T_{r}\right) \cong h_{f}\left(T_{r}\right) \cdot a_{t h} \cdot D_{c} \cdot\left(1-\frac{D_{c}}{D_{c}}\right)
\end{aligned}
$$

where; $\varepsilon_{g}=(\gamma+1) /(2 \gamma-2), \mathrm{a}_{\mathrm{th}}$ is the mass accommodation coefficient, $\zeta$ is the thermal accommodation coefficient and $h_{f}\left(T_{r}\right)$ is the enthalpy of the condensate at $T_{r}$. 


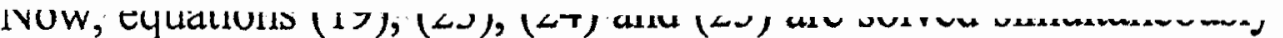

iterative procedure to obtain the three unknowns dr/dt, $T_{r}$ and $P_{r}\left(T_{r}\right)$.

\section{FORMULATION OF FLOW DIFFERENTIAL EQUATIONS:}

Owing to the assumption that the condensation occurs only downstream of the nozzle throat, variations of the flow properties along the convergent section are obtained using the well-known equations of isentropic flow [24] for $\mathrm{A} / \mathrm{A}^{*}, \mathrm{~T} / \mathrm{T}_{0}, \mathrm{P} / \mathrm{P}_{\mathrm{o}}$ and $\rho / \rho_{\mathrm{o}}$. But for condensing flow in the divergent section the following equations are obtained.

Differentiation of equations (1), (2) and (9) gives

$$
\begin{aligned}
& \frac{1}{P} \cdot d P=\frac{1}{\rho_{m}} \cdot d \rho_{m}+\frac{1}{T_{g}} \cdot d T_{g}-\frac{1}{M} \cdot d M \\
& \frac{1}{M} \cdot d M=-\left(1-\frac{M}{M_{g}}\right) \cdot \frac{1}{1-G} \cdot d G
\end{aligned}
$$

and

$$
\frac{1}{\rho_{u}} \cdot d \rho_{m}+\frac{1}{C} \cdot d C+\frac{1}{A} \cdot d A+\frac{1}{1-G} \cdot d G=0
$$

Combining Eqs. (26) and (27) yields to

$$
\frac{1}{\rho_{m}} \cdot d \rho_{m}=\frac{1}{P} \cdot d P-\frac{1}{T_{g}} \cdot d T_{g}-\left(1-\frac{M}{M_{g}}\right) \cdot \frac{1}{1-G} \cdot d G
$$

Introducing the definition of frozen Mach number $\left[\mathrm{Ma}=\mathrm{C} /\left(\gamma \mathrm{P} / \rho_{\mathrm{m}}\right)^{1 / 2}\right]$ into Eq. (10), with the aid of Eq. (9), results in

$$
\frac{1}{C} \cdot d C=-\frac{1-G}{\gamma(M a)^{2}} \cdot \frac{1}{P} \cdot d P
$$

Considering the enthalpies of carrier gas (air) and vapour besides the isobaric heat capacity of vapour-air mixture under the ideal gas assumptions to be

$$
\begin{aligned}
& h_{a}=c_{p u} \cdot T_{g} \\
& , h_{g}=c_{p s} \cdot T_{g}
\end{aligned}
$$

and

$$
c_{p}=\frac{1-\mu}{1-G} \cdot c_{p a}+\frac{\mu-G}{1-G} \cdot c_{p g}
$$

The isobaric heat capacity of vapour-air mixture is reduced at the nozzle inlet to

$$
c_{j k s}=\left(1-\mu_{0}\right) \cdot c_{p a}+\mu_{0} \cdot c_{p p}
$$

Substituting the last definitions (31.a), (31.b) and (31.d) into the energy equation, changes Eq. (18) to 


$$
d\left[\frac{C^{2}}{2}+c_{p o} \cdot T_{g}-G \cdot h_{f g}\right]=0
$$

Differentiation of the last equation gives

$$
\begin{aligned}
& C \cdot d C+c_{p o} \cdot d T_{g}-G \cdot d h_{f g}-h_{f g} \cdot d G=0 \\
\text { or } \quad & C . d C+\left(c_{p o}-G \cdot \frac{d h_{f g}}{d T_{g}}\right) \cdot d T_{g}=h_{f g} \cdot d G
\end{aligned}
$$

Equations (32.a and 32.b) can be rewritten in the following form

$$
\left[\frac{C^{2}}{\left(c_{p x t}-G_{\cdot} \cdot \frac{d h_{f k}}{d T_{g}}\right) \cdot T_{g}}\right] \cdot \frac{d C}{C}+\frac{d T_{g}}{T_{g}}=\frac{h_{f g}}{\left(c_{p o}-G \cdot h_{f g}\right) \cdot T_{g}} \cdot d G
$$

Inserting the Mach number definition into Eq. (33) changes it to

$$
\left[\frac{(M a)^{2} \cdot \gamma \cdot P}{\left(c_{p o}-G \cdot \frac{d h_{f g}}{d T_{g}}\right) \cdot T_{g}}\right] \cdot \frac{d C}{C}+\frac{d T_{g}}{T_{g}}=\frac{h_{f g}}{\left(c_{p o}-G \cdot \frac{d h_{f g}}{d T_{g}}\right) \cdot T_{g}} \cdot d G
$$

Using the definition of $P$ from Eq. (1) in Eq. (34) results in

$$
\left[\frac{(M a)^{2} \cdot R_{g} \cdot \gamma}{M\left(c_{p o}-G \cdot \frac{d h_{f g}}{d T_{g}}\right)}\right] \cdot \frac{d C}{C}+\frac{d T_{g}}{T_{g}}=\frac{h_{f g}}{\left(c_{p o}-G \cdot \frac{d h_{f g}}{d T_{g}}\right) \cdot T_{g}} \cdot d G
$$

Now, the term (dC/C) is eliminated from Eqs. (35) and (28) with the aid of Eq. (30) to get

$$
\frac{1}{T_{g}} \cdot d T_{g}=\left[\frac{R_{g} \cdot(1-G)}{M\left(c_{p o}-G \cdot \frac{d h_{f g}}{d T_{g}}\right)}\right] \cdot \frac{1}{P} \cdot d P+\left[\frac{h_{j g}}{\left(c_{p o}-G \cdot \frac{d h_{f g}}{d T_{g}}\right) \cdot T_{g}}\right] \cdot d G
$$

and $\quad \frac{1}{\rho_{m}} \cdot d \rho_{m}-\left[\frac{1-G}{\gamma(M a)^{2}}\right] \frac{1}{P} \cdot d P+\frac{1}{A} \cdot d A+\frac{1}{1-G} \cdot d G=0$

Replacing $\left(d T_{g} / T_{g}\right)$ in Eq. (29) by Eq. (36) changes $\left(d \rho_{m} / \rho_{m}\right)$ to be

$$
\frac{1}{\rho_{m}} \cdot d \rho_{m}=\left[1-\frac{R_{g} \cdot(1-G)}{M\left(c_{p o}-G \cdot \frac{d h_{f g}}{d T_{g}}\right)}\right] \cdot \frac{1}{P} \cdot d P-\left[\frac{h_{f g}}{\left(c_{p o}-G \cdot \frac{d h_{f g}}{d T_{g}}\right) \cdot T_{g}}+\frac{\left(1-\frac{M}{M_{g}}\right)}{1-G}\right] \cdot d G
$$




$$
\begin{aligned}
& {\left[1-\frac{R_{k}(1-G)}{M\left(c_{p o}-G \cdot \frac{d h_{f g}}{d T_{g}}\right)}-\frac{1-G}{\gamma(M a)^{2}}\right] \cdot \frac{1}{P} \cdot d P-\left[\frac{h_{f g}}{\left.\frac{d h_{f g}}{d}\right) \cdot T_{g}}-\frac{1}{1-G}+\right.} \\
& \left.\frac{1}{1-G}\left(1-\frac{M}{M_{g}}\right)\right] \cdot d G+\frac{1}{A} \cdot d A=0
\end{aligned}
$$

Equation (39) can be rearranged to obtain a differential equation for $\mathrm{dP}$ as

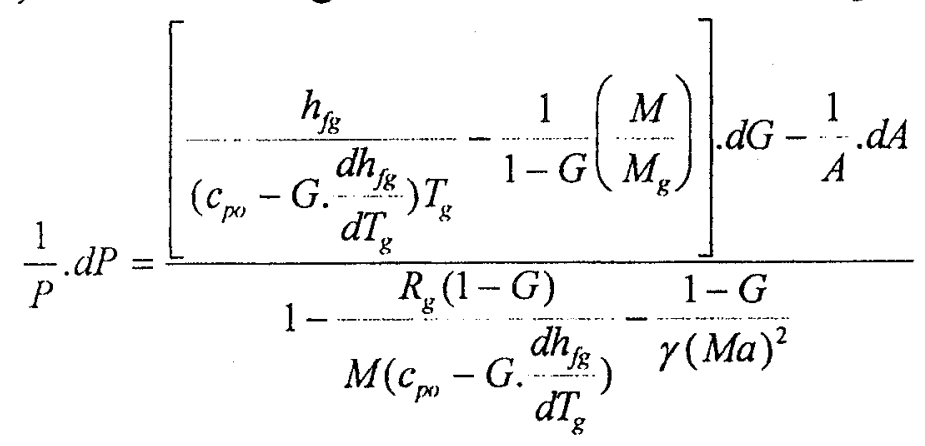

In order to integrate Eq. (40) numerically; $\mathrm{G}, \mathrm{dG}$ and $\left(\mathrm{dh}_{\mathrm{fg}} / \mathrm{dT}_{\mathrm{g}}\right)$ are defined and obtained numerically. Condensate mass fraction at a location $\mathrm{x}$ along the nozzle axis is defined by

$$
G=G(x)=\frac{4 \pi}{3} \frac{\rho_{f}}{\dot{m}} \int_{-\infty}^{x} J(\xi) \cdot A(\xi) \cdot[r(x, \xi)]^{3} \cdot d \xi
$$

and $\quad r(x, \xi)=r_{c r}(\xi)+\int_{\xi}^{x} \frac{\partial(x, \xi)}{\partial x} \cdot d \xi$

where $J(\xi)$ : nucleation rate per unit volume,

$$
\dot{m} \text { : mass flow rate of condensed vapour, }
$$

and $r(x, \xi)$ : final radius at the location $x$ of a droplet nucleated at $\xi$. Differentiation of Eq. (41) gives

$$
\frac{d G}{d x}=\frac{4 \pi}{3} \cdot \frac{\rho_{f}}{\dot{m}} \cdot J(x) \cdot A(x) \cdot\left[r_{c r}(x)\right]^{3}+\frac{4 \pi \rho_{f}}{\dot{m}} \int_{-\infty}^{x} J(\xi) \cdot A(\xi) \cdot[r(x, \xi)]^{2} \cdot \frac{\partial}{\partial x} \cdot d \xi
$$

When condensation occurs, there are different categories of droplets with different sizes born at different locations and grow up with different growth rates. Formulation of the local size of the condensed droplets $\{r(x, \xi)\}$ by Eq. (42) is followed with correlating the so-called "mean radii" of all condensed droplets in the flow. Here, the volume average (or the mass mean) radius is calculated as 


$$
r_{m}=\left\{\frac{\int_{-\infty}^{x}[r(x, \xi)]^{3} \cdot J(\xi) \cdot\left[\frac{A(\xi)}{A^{*}}\right] \cdot d \xi}{\int_{-\infty}^{x} J(\xi) \cdot\left[\frac{A(\xi)}{A^{*}}\right] \cdot d \xi}\right\}^{1 / 3}
$$

Thus, the differentiation $\left(\mathrm{dh}_{\mathrm{fg}} / \mathrm{dT}_{\mathrm{g}}\right)$ for the tested vapours is obtained here using the simplification suggested in $[7,19 \& 25]$ for the heat of phase transition $\left(\mathrm{h}_{\mathrm{fg}}\right)$ to be

$$
h_{f g}\left(T_{g}\right)=h_{f g_{o}}+\Delta h_{f g} \cdot\left(T_{g}-273\right)
$$

Where $h_{\mathrm{fgo}}$ is the heat of phase transition at $273 \mathrm{~K}$ and $\Delta \mathrm{h}_{\mathrm{fg}}$ is the temperature correspondence for the heat of phase transition. Therefore, the differentiation $\left(\mathrm{dh}_{\mathrm{fg}} / \mathrm{dT}_{\mathrm{g}}\right)$ is obtained from Eq. (45) and expressed as

$$
\frac{d h_{f g}}{d T_{g}}=\Delta h_{f g}
$$

Finally, the differentials $d T_{\mathrm{g}}, \mathrm{dC}$ and $\mathrm{d} \rho_{\mathrm{m}}$ are defined by Eqs. (36), (35) and (29). Whereas, the saturation temperature corresponding to the flow pressure is calculated using Clausius-Clapeyron equation which defined as

$$
d T_{s}=\frac{R_{g} \cdot T_{s}^{2}}{h_{f g}} \cdot \frac{1}{P} \cdot d P
$$

\section{SOLUTION PROCEDURE:}

Under the assumptions (a) and (b) in section 2, the mixture of organic vapour and inert carrier gas expands isentropically and without change in its composition along the convergent section of the tested nozzle. The flow properties along the convergent section are obtained from the isentropic relations which were reported in many textbooks \{(e.g. Douglas, et al. $[24]\}$. When appreciable condensation occurs on the organic vapour within the divergent section, an amount of heat addition corresponding to the latent heat of condensed vapour (i.e. $q=G$. $h_{\mathrm{fg}}$ ) is transferred to the unit mass of the expanding mixture. This amount of heat transfer can drive the flow Mach number towards unity (i.e., chocking occurrence). Therefore, the maximum amount of heat that may be added to a unit mass in a condensing flow was defined by Wegener [16] to not be exceeded, at any situation in nozzle passage, the value

$$
q_{\max }=c_{p o} \cdot T_{o}\left\{\frac{\left[(M a)^{2}-1\right]^{2}}{2(\gamma+1) \cdot(M a)^{2} \cdot\left[1+\frac{(\gamma-1) \cdot(M a)^{2}}{2}\right]}\right\}
$$

Now, in order to predict the variations of $P, T_{s}, T_{g}, C$ and $\rho_{m}$ and consequently the changes in $J, r$ and $G$; equations (40), (47), (36), (30), (38), 


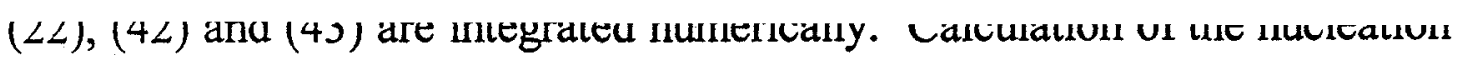
rate from $\mathrm{Eq}$. (22) requires a knowledge about the two factors $\Gamma$ and $\Phi$. The factor $\Gamma$ is used in the present study with the recommended values of Wegener et al [19], Wu [20] and Dawson et al [29]. While the factor $\Phi$ is estimated during calculations depending on the local thermodynamic properties of the tested vapour. Table 1 presents a sample of the calculated values of $\Phi$ for the investigated vapour at the atmospheric pressure. If it is assumed a priori that thermal chocking does not occur and that the pressure ratio across the nozzle is sufficient to produce supersonic flow, these equations can be integrated in the downstream direction as an initial value problem on the basis of Rung-Kutta-Merson method and using a "standard time marching technique".

\section{Table 1: A list of the calculated values of the factor $\Phi$ and the "non-isothermal" correction factor for the tested organic vapours at atmospheric pressure.}

\begin{tabular}{|c|c|c|c|}
\hline Factor & Freon-11 & Ammonia & Ethanol \\
\hline$\Phi$ & 37.894 & 36.4075 & 30.50 \\
\hline $1 /(1+\Phi)$ & 0.0257 & 0.0267 & 0.0317 \\
\hline
\end{tabular}

The area distribution $\mathrm{A} / \mathrm{A}^{*}$ is required here to complete the theoretical modeling for the problem of condensing flows in supersonic nozzles. This area distribution is obtained from a noncondensing calibration run. The obtained experimental pressure distribution along the nozzle, $\mathrm{P}(\mathrm{x})$, is used to compute the area distribution from the isentropic flow relations [24]. The computed area distribution is fitted numerically to gain the nozzle area distribution as a polynomial in $\mathrm{x}$. The present research utilizes the geometries of two nozzles were fitted by Barschdorff [26] and Wegener and Pouring [27]. These geometries or area distributions are used here as polynomials and denoted by "nozzle (1)" and "nozzle (2)" respectively.

Finally, the properties of the investigated vapours are required here to complete the present model equations. These properties include the equilibrium vapour pressure $\left(\mathrm{P}_{\infty}\right)$, condensate density $\left(\rho_{\mathrm{f}}\right)$, the bulk surface tension $\left(\sigma_{\infty}\right)$, heat of phase transition $\left(h_{\mathrm{fg}}\right)$, ratio of specific heats for the vapour $(\gamma)$ and the molecular weight $(\mathrm{M})$. All these properties except both $\mathrm{M}$ and $\gamma$ are functions of the vapour temperature. The published correlations of these properties are collected and presented in Appendix (A). These correlations are expressed as functions of vapour temperature in ${ }^{\circ} \mathrm{C}$ or $\mathrm{K}$. Only two properties still without definition, which are required in calculating Eqs. (19) and (24.b). These properties are the surface tension on the curved surface of the condensed droplets $(\sigma)$ and the saturation vapour 
pressure over the droplet surface $\left\{\mathrm{P}_{\mathrm{r}}\left(\mathrm{T}_{\mathrm{r}}\right)\right\}$. The surface tension on the droplet surface is combined with the bulk surface tension (i.e., the surface tension on a flat liquid surface) by Tolman [28] in the following expression

$$
\frac{\sigma}{\sigma_{\infty}}=\frac{1}{1+\frac{2 \delta}{r}}
$$

where $\delta$ is a constant corresponding to the condensed vapour $[28,16]$ and $\sigma_{\infty}$ is the bulk surface tension. Correlations of $\sigma_{\infty}$ are given in Appendix (A).

The saturation vapour pressure over the droplet surface is defined due to $[19,20]$ by

$$
P_{r}\left(T_{r}\right)=P_{\infty}\left(T_{r}\right) \exp \left(\frac{2 \sigma M_{f}}{k T_{g} \rho_{f} r}\right)
$$

All the required equations for the present model are completed now. Therefore, a computer program concerning with the solution of the above described system of equations is developed, tested and operated.

\section{RESULTS AND DISCUSSION:}

Theoretical results presented in Figures 1-6 show the effects of changing the initial values of both vapour temperature and mass fraction of the tested vapour on the flow and condensation characteristics during expansions of freon-11, ethanol and ammonia through supersonic nozzles. Flow characteristics are presented here by both the pressure and Mach number variations $\left(\mathrm{P} / \mathrm{P}_{\mathrm{o}}\right.$ and $\left.\mathrm{Ma}\right)$ whilst the condensation characteristics are simulated by the supersaturation ratio (S), amount of vapour subcooling $(\Delta T)$, nucleation rate (as $\log J)$, critical radius of nucleated droplets $\left(\mathrm{r}_{\mathrm{cr}}\right)$, mean radius of condensed droplets $\left(\mathrm{r}_{\mathrm{m}}\right)$ and the dimensionless mass fraction of condensate $\left(\mathrm{G} / \mathrm{G}_{0}\right)$. All the predictions presented here illustrate the changes in flow and condensation characteristics of the tested vapour along the divergent section of the utilized nozzle. The tested nozzles are described in section (4) and denoted as nozzle (1) and nozzle (2). Geometries of the divergent sections of these nozzles are shown in Figures (1.a), (3.a) and (5.a). Here, it is of great importance to note that the predictions of Figures 1-6 start from a location downstream of nozzle throat (i.e., when the flow becomes supersonic). Figure 1 indicates that as the inlet vapour temperature $\left(\mathrm{T}_{\mathrm{go}}\right)$ of freon-11 increases at the entrance of the nozzle (1); $S, \Delta T, \log J, r_{m}$ and $G / G_{o}$ are decreased and $r_{c r}$ is increased 


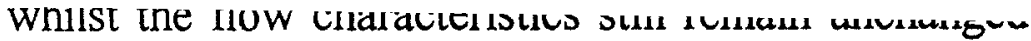

be explained by the fact that as the vapour temperature increases both the amount of subcooling and supersaturation ratio are decreased and consequently the rate of nucleation and the condensation rate are decreased also as illustrated in Figures (1.b) and (1.d). Furthermore, decreasing $\Delta T$ and $S$ tends to increase the size of nucleated droplets as expected from Eq.(19) and then decrease the mean size of condensed droplets. This is because decreasing $\Delta \mathrm{T}$ in the denominator of Eq.(19) and consequently increasing $T_{g}$ in the right side of Eq. (23.a) tends to increase $r_{c r}$ and to decrease the rate of droplet growth respectively. It can be noticed also in Figures (1.c) and (1.d) that freon-11 at $\mathrm{T}_{\mathrm{go}}=238.56 \mathrm{~K}$ passes through the nozzle without condensation \{i.e.; as a supersaturated vapour represented by curve 3 for $r_{c r}$ only in Figure (1.c)\} but changing its temperature to $201.56 \mathrm{~K}$ and $201.0 \mathrm{~K}$ makes the condensation to appear at different locations along the nozzle axis (condensation occurs at $\mathrm{x} / \mathrm{L}=0.3176$ with $\mathrm{T}_{\mathrm{go}}=201.0 \mathrm{~K}$ and at $\mathrm{x} / \mathrm{L}=0.6941$ when $\mathrm{T}_{\mathrm{go}}=201.56 \mathrm{~K}$ ). Here, it can be concluded that increasing $T_{\mathrm{go}}$ of freon- 11 from $201.0 \mathrm{~K}$ to $201.56 \mathrm{~K}$ moves the condensation onset (i.e., the location at which the amount of subcooling appears in the calculations and the mean size of droplets differ from the critical one) towards the nozzle exit. The reason for the constancy of the predicted values of $\mathrm{P} / \mathrm{P}_{\mathrm{o}}$ and $\mathrm{Ma}$ with different values of $\mathrm{T}_{\mathrm{go}}$ in Figure (1.a) may be due to the small differences between the rates of heat transferred to the vapour phase by the condensation upon the droplets of these cases.

Figure 2 illustrates the effect of the value of freon-11 mass fraction on the flow and condensation characteristics. Figure (2.a) shows that increasing $\mu$ from 0.16 to 0.20 has no effect on both $\mathrm{P} / \mathrm{P}_{\mathrm{o}}$ and $\mathrm{Ma}$ (curve $1,2)$ while its increasing to the value of 0.25 increases the predicted values of $\mathrm{P} / \mathrm{P}_{\mathrm{o}}$ and $\mathrm{Ma}$ (curve 3) compared to those at $\mu=0.16$ and $\mu=0.20$. This is because the value of $\mu=0.25$ leads to higher values of the condensation parameters: $S, \Delta \mathrm{T}, \log \mathrm{J}$ and $\mathrm{r}_{\mathrm{m}}$ as shown in Figures (2.b, 2.c and 2.d). For example; the nucleation rates at the nozzle exit for the three tested values of $\mu$ (i.e. $0.16,0.20$ and 0.25 ) are as $J=5.83,2.24 \times 10^{3}$ and $2.73 \mathrm{x}$ $10^{5} \mathrm{~m}^{-3} \mathrm{~S}^{-1}$. Therefore, higher rates of heat of phase transition accompanying the higher nucleation rates are transferred within the mixture and causes increase of the flow pressure and, in turn, decrease the flow Mach number.

Variations of the flow and condensation characteristics for ethanol expansion through nozzle (2) with different values of the initial vapour temperature and different mass fraction are presented in Figures 3 and 4. Flow characteristics in Figure (3.a) indicate the same tendency as was noticed with freon-11 in Figure (1.a). However, increasing the vapour 
temperature causes diminishing all of the condensation variables as shown clearly in Figures (3.b), (3.c) and (3.d). The calculations show that increasing ethanol temperature from $305 \mathrm{~K}$ to $315 \mathrm{~K}$ yields to decrease of $\log \mathrm{J}$ from 12.6945 (corresponding to $\mathrm{J}=4.95 \times 10^{12} \mathrm{~m}^{-3} \mathrm{~S}^{-1}$ ) to 4.9622 (according to $\mathrm{J}=9.17 \times 10^{4} \mathrm{~m}^{-3} \mathrm{~S}^{-1}$ ) at the nozzle exit as devised from Figure (3.b). Furthermore, increasing the ethanol temperature moves the point of condensation onset towards the nozzle exit. At this point, the numerical results reveal that the condensation onset of ethanol occurs inside nozzle (2) at $\mathrm{x}=1.6 \mathrm{~cm}$ downstream the throat for $\mathrm{T}_{\mathrm{go}}=305 \mathrm{~K}$, at $\mathrm{x}=3.2 \mathrm{~cm}$ with $\mathrm{T}_{\mathrm{go}}=310 \mathrm{~K}$ and at $\mathrm{x}=4.9 \mathrm{~cm}$ when $\mathrm{T}_{\mathrm{go}}=315 \mathrm{~K}$. In the distance between nozzle throat and the point of condensation onset, it can be noticed the existence of nucleated droplets with decreased sizes only as shown in Figure (3.c). Downstream the point of condensation onset, nucleated droplets grow up through the condensation process and reach to higher sizes comparing to its initial size at the onset point. For example; the nucleated droplets of ethanol vapour with a temperature of $305 \mathrm{~K}$ starts to grow by condensation from a critical radius of $1.362 \times 10^{-3} \mu \mathrm{m}$ at the point of condensation onset which lies at a point $1.6 \mathrm{~cm}$ downstream the throat to a final radius of $4.095 \times 10^{-2} \mu \mathrm{m}$ at the nozzle exit. This example indicates that the nucleated ethanol droplets grow along a distance of 4.4 $\mathrm{cm}$ before the nozzle exit to about 30 times its critical (initial) size as depicted by curves (1) in Figure (3.c). The reasons for these tendencies are discussed previously with the results of freon-11 in Figure 1. It is of great importance to note that the trend of predictions of Wegener, et al.[19], for the variations of condensation characteristics during ethanol expansion through a supersonic nozzle, agrees with the present findings. Plots of Figure 4 summarize the changes in the predicted flow and condensation characteristics with increasing the mass fraction of ethanol from 0.05 to 0.15 during the expansion of air-ethanol mixture in nozzle (2). The flow characteristics in Figure (4.a) shows that increasing the mass fraction of ethanol causes increase of the flow pressure and consequently decrease of the Mach number along the nozzle divergent section. It is evident also in Figure (4.a) that the air expansion with a mass fraction of ethanol equals 0.15 has a pressure bump downstream the throat section. Pressure increase by increasing $\mu$ in Figure (4.a) was reported previously by Wegener, et al. [19] and $\mathrm{Wu}[20]$. They explained the pressure increase by the heat addition to the vapour during condensation. Figure (4.b) indicates that increasing $\mu$ tends to advance the nucleation in the direction of nozzle throat and then decreases the supersaturation ratio towards the nozzle exit. It should be noted that with $\mu=0.05, \log \mathrm{J}$ starts to increase from the location of condensation onset at $2.3 \mathrm{~cm}$ (i.e., $\mathrm{x} / \mathrm{L}=0.3286$ ) downstream the throat and along the remainder portion of the divergent section. Also, 
increases monotonically to a maximum value at a location $2.5 \mathrm{~cm}$ (i.e., $x / L=0.357$ ) downstream the throat and then vanishes (or the nucleation is stopped). With increasing $\mu$ to 0.15 , a similar trend to those showed with $\mu=0.10$ is obtained for $\log \mathrm{J}$ variation at $1.4 \mathrm{~cm}$ (i.e., $x / L=0.2$ ) downstream the nozzle throat except the rapid decrease of $\log \mathrm{J}$ (curve 3) compared with the gradual decrease of the preceding case (curve 2). In Figure (4.c), it can be noticed the different behaviors for $r_{c r}$ and $r_{m}$ variations along the nozzle divergent section. For the case of $\mu=0.05$ whereas $S$ and $\log J$ increase monotonically curves 1 in Figure (4.b)\}, the predicted variations of $r_{c r}$ and $r_{m}$ as represented by curves 1 in Figure (4.c) are a slight decrease and a gradual increase respectively. This behavior corresponds to the beginning of condensation by the free molecular regime. Generally speaking, the critical sized clusters are showed in Figure (4.c) to be stopped in generation when the nucleation disappeared (i.e., at the point of $\log \mathrm{J}$ vanishing). Growth of existing droplets continue along the nozzle divergent section in different rates as given by curves 1,2 and 3 for $r_{m}$ in Figure (4.c). Variations of $\Delta \mathrm{T}$ and $\mathrm{G} / \mathrm{G}_{0}$ with changing $\mu$ are shown in Figure (4.d) similar to the variations of $S$ and $r_{m}$ in Figures (4.b) and (4.c) respectively.

Figures 5 and 6 illustrate the influence of both the inlet vapour temperature and the mass fraction on the variations of flow and condensation characteristics for ammonia expansion through nozzle (2). These figures show the same tendencies as was discussed in the condensation of freon-11 and ethanol. For example, increasing the ammonia inlet temperature leads to delay of the condensation onset towards nozzle exit and decreasing the nucleation rate, amount of subcooling (or supersaturation ratio), mean radius of the condensed droplets and the rate of condensation as showed in Figure 5. While it can be concluded from the predictions of Figure 6 that increasing the ammonia mass fraction tends to advance the point of condensation onset towards the nozzle throat and to increase $\log J, \Delta T, r_{m}$ and $G / G_{o}$ along the tested nozzle.

In order to distinguish between the condensation characteristics of the tested organic vapours, a comparison between these characteristics has been carried out here. Results of this comparison are released in Figure 7 and Table 2. This comparison is held between saturated vapours at the entrance of nozzle (2). The comparison indicates that the condensation process starts faster in freon-11 and results in larger sizes for the nucleated droplets and the condensed ones. Ethanol and ammonia are followed freon-11 on the condensation starting and on the sizes of nucleated 
clusters. However, comparison between the predicted nucleation rates show different regimes. Dawson, et al [29] have showed that ethanol has molar surface entropy less than those of reon-11 and ammonia. They concluded that the higher molar surface entropies of freon-11 and ammonia are the reason for the low nucleation rates of these vapours. It is of great importance to note that the predictions presented in Table 2 are qualitatively similar to those reported for steam condensation [21].

Table 2: A comparison between the predicted condensation characteristics of the tested organic vapours at a location $4.2 \mathrm{~cm}$ downstream of nozzle (2) throat where $\mathrm{A} / \mathrm{A}^{*}=1.2841$.

\begin{tabular}{|c|c|c|c|c|c|c|c|c|c|c|}
\hline Vapour & $M$ & $\gamma$ & P,Torr & $\Lambda \mathrm{T}, \mathrm{K}$ & $\mathrm{X}_{\text {onssed }}, \mathrm{cm}$ & $\log \mathrm{J}$ & $\mathrm{J}, \mathrm{m}^{-3} \mathrm{~S}^{-1}$ & $I_{r} \times 10^{-1}, \mu_{m}$ & $\mathrm{r}_{\mathrm{m}}, \mu_{\mathrm{m}}$ & $\mathrm{G} / \mathrm{G}_{0}$ \\
\hline Freon-11 & 137.38 & 1.13 & 206.3 & 11.34 & 1.3 & 1.1876 & & 9.0024 & 0.56146 & $4.3926 \times 10^{-13}$ \\
\hline Ethanol & 46.07 & 1.13 & 206.3 & 15.45 & 1.6 & 11.2413 & $1.743 \times 10^{11}$ & 8.7724 & 0.02109 & $6.6098 \times 10^{-8}$ \\
\hline Ammonia & 17.03 & 1.31 & 178.2 & 3.77 & 3.8 & 4.7625 & $5.788 \times 10^{4}$ & 6.1014 & 0.00093 & $5.5949 \times 10^{-19}$ \\
\hline
\end{tabular}

${ }^{*} \mathrm{x}_{\text {onset }}$ is the distance in [cm] between nozzle throat and location of condensation onset.

Finally, predictions of the present model for pressure distribution along three supersonic nozzles are compared to the published measured ones in Figure 8. Furthermore, a comparison between the present predicted pressure distribution of ethanol expansion through a supersonic nozzle and a published prediction [20] is given also in Figure 8. The predicted pressure distribution is presented here in dimensionless form $\left(\mathrm{P} / \mathrm{P}_{\mathrm{o}}\right)$ with ammonia and freon-11 and is released as absolute values in [Torr] for ethanol. Utilizing absolute values of the pressure distribution in Figure (8.b) is to declare the degree of conformity between present predictions and measurements. The good agreement appeared in the comparisons of Figure 8 confirms the present model.

\section{CONCLUSIONS:}

The theoretical results released in this paper appear to give a reasonable description for the condensation behavior of some organic vapours during supersonic flow in a convergent-divergent nozzle. Classical nucleation theory is utilized in the present work after introducing a numerical factor into the equation of the classical nucleation rate. This new factor $(\beta)$ combines both the non-isothermal correction of Young [22] and the numerical correction of Wegener, et al [19] and $\mathrm{Wu}$ [20]. Besides, modified equations for both the droplets surface tension and the thermodynamic properties of the condensing vapours are introduced here. The theoretical results obtained here show that increasing the organic vapour temperature as well as decreasing its mass fraction delayed the 
increase of the organic vapour temperature or the decrease of the vapour mass fraction results in lowering the predicted nucleation rate, amount of subcooling (or the supersaturation ratio), final size of the condensed droplets and the mass fraction of the condensate. However, the present predictions of condensation characteristics are, qualitatively, coincide to those of steam condensation. Experiments reported on pressure measurements during the condensation of ammonia, ethanol and freon-11 through supersonic nozzles are follow the present model predictions.

\section{LIST OF SYMBOLS:}

A. nozzle cross-sectional area $\left[\mathrm{m}^{2}\right]$,

$a_{\text {th }}$ mass accommodation coefficient,

C flow velocity $\left[\mathrm{ms}^{-1}\right]$,

$c_{p} \quad$ isobaric specific heat capacity $\left[\mathrm{KJ}_{\mathrm{N}} \mathrm{Kg}^{-1} \cdot \mathrm{K}^{-1}\right]$,

$c_{f} \quad$ specific heat capacity of condensate $\left[\mathrm{KJ} \cdot \mathrm{Kg}^{-1} \cdot \mathrm{K}^{-1}\right]$,

$D_{c}$ rate of impingement (or condensed) vapour molecules on the droplet surface $\left[\mathrm{S}^{-1}\right]$,

$D_{e} \quad$ rate of evaporated vapour molecules from the droplet surface $\left[\mathrm{S}^{-1}\right]$,

$\mathrm{G}$ mass fraction of condensate,

h specific enthalpy [KJ.Kg-1],

$\mathrm{J}$ nucleation rate $\left[\mathrm{m}^{-3} \cdot \mathrm{S}^{-1}\right]$,

k Boltzmann's constant $\left[=1.38 \times 10^{-23} \mathrm{~J} . \mathrm{K}^{-1}\right]$,

$\mathrm{L}$ length of the divergent section of the tested nozzle $[\mathrm{cm}]$,

M molecular weight,

Ma Mach number,

$\mathrm{m}$ mass fraction of mixture species-mass of one molecule $\left[=2.99 \times 10^{-26} \mathrm{Kg}\right.$,

$\dot{m}$ mass flow rate of gas-condensate mixture $\left[\mathrm{Kg} \cdot \mathrm{S}^{-1}\right]$,

$\mathrm{P} \quad$ pressure [Torr, bar],

$\mathrm{q}_{\mathrm{c}}$ mass condensation coefficient,

$q_{\max }$ maximum amount of heat added to a unit mass of condensed vapour $\left[\mathrm{KJ} . \mathrm{Kg}^{-1}\right]$,

$\mathrm{R}_{\mathrm{g}}$ molar gas constant in Eqs. (1-5) $\left[=8314.3 \mathrm{~J} \cdot \mathrm{kmol}^{-1} \cdot \mathrm{K}^{-1}\right]$ or specific gas constant in Eqs. (19\&21) [J. $\mathrm{Kg}^{-1} \cdot \mathrm{K}^{-1}$,

$\mathrm{r} \quad$ droplet radius $[\mu \mathrm{m}]$,

$\mathrm{S} \quad$ supersaturation ratio $\left\{\mathrm{S}=\mathrm{P} / \mathrm{P}_{\mathrm{s}}\left(\mathrm{T}_{\mathrm{g}}\right)\right\}$,

$\mathrm{T}$ temperature $\left[\mathrm{K},{ }^{\circ} \mathrm{C}\right]$,

$\mathrm{x}$ co-ordinate along the nozzle axis [m],

$\beta \quad$ numerical coefficient $\{$ Eq.(22)\}, 
$\Gamma \quad$ numerical coefficient $\{$ Eq.(21.b) $\}$

i isentropic exponent,

$\Delta \mathrm{G}_{\mathrm{cr}}$ critical free energy barrier [N.m $\left.\mathrm{m}^{-1}\right]$,

$\Delta \mathrm{h}_{\mathrm{fg}}$ temperature correspondence for the heat of phase transition $\left[\mathrm{KJ} . \mathrm{K}_{\mathrm{g}}^{-1} \cdot \mathrm{K}^{-1}\right.$ ],

$\Delta \mathrm{T} \quad$ vapour subcooling $\left\{\Delta \mathrm{T}=T_{s}(\mathrm{P})-T_{g}\right\}[\mathrm{K}]$,

$\zeta \quad$ thermal accommodation coefficient,

$\mu$ mass fraction of the organic substance in the mixture,

$\xi \quad$ value of $\mathrm{x}$ where droplet is born [m],

$\rho \quad$ mass density $\left[\mathrm{Kg} \cdot \mathrm{m}^{-3}\right]$,

$\sigma \quad$ surface tension $\left[\mathrm{N} \cdot \mathrm{m}^{-1}\right]$,

$\Phi \quad$ numerical factor $\{$ Eq.(21.a)\}.

\section{Superscripts:}

referred to the volume of gaseous phase,

* at throat; critical.

\section{Subscripts:}

a air,

cl referred to classical theory of nucleation,

cr critical,

f condensate,

fg of phase transition,

$\mathrm{g}$ gas; vapour,

$\mathrm{m}$ mixture of inert gas and condensing vapour,

0 inlet,

$\mathrm{r}$ on the droplet surface,

s saturation,

$t$ mixture of gas-condensate,

$\infty$ on a flat surface.

ni non-isothermal

\section{Appendix (A): Thermodynamic properties of the tested vapours}

The following are the liquid density in $\left[\mathrm{Kg} / \mathrm{m}^{3}\right]$, vapour pressure on flat surface in [bar], heat of phase transition in $[\mathrm{KJ} / \mathrm{Kg}]$ and surface tension in $[\mathrm{dyn} / \mathrm{cm}$ ] for freon-11, ethanol and ammonia. References of these correlations are listed here.

i- Freon-11 [29]:

$\rho_{\mathrm{f}}=1.53 \times 10^{3}-2.5(\mathrm{~T}-273)$ 
$\left.\left.P_{\infty}=0.4013 \exp \left\{-\left(\frac{279.687}{273.2 R_{g}}\right)\left(\frac{273.2}{T}-1\right)\right]-\left(\frac{0.51}{R_{g}}\right) \ln \left(\frac{1}{273.2}\right)\right]\right\}$

$\mathrm{h}_{\mathrm{fg}}=195.105-0.31(\mathrm{~T}-273)$

$\sigma_{\infty}=21.7-0.137(\mathrm{~T}-273)$

where $\mathrm{T}$ is in $[\mathrm{K}]$

ii- Ethanol [19]:

$\rho_{\mathrm{f}}=806.25-0.845 \mathrm{~T}+29 \times 10^{-5} \mathrm{~T}^{2}$

where $\mathrm{T}$ is in $\left[{ }^{\circ} \mathrm{C}\right]$

$P_{\infty}=0.0163 \exp \left\{-\left[\frac{1203.956}{273.2 R_{g}} \cdot\left(\frac{273.2}{T}-1\right)-\frac{0.921}{R_{g}} \ln \left(\frac{T}{273.2}\right)\right]\right\}$

where $\mathrm{T}$ is in $[\mathrm{K}]$

$\mathrm{h}_{\mathrm{fg}}=946.217-0.8918 \mathrm{~T}-0.00578 \mathrm{~T}^{2}$

where $\mathrm{T}$ is in $\left[{ }^{\circ} \mathrm{C}\right]$

$\sigma_{\infty}=23.97-0.085 \mathrm{~T}$

where $\mathrm{T}$ is in $\left[{ }^{\circ} \mathrm{C}\right]$

iii- Ammonia [7]:

$\rho_{f}=642-1.19(\mathrm{~T}-273)$

$P_{\infty}=0.08666 \exp \left\{-\left[\frac{1457.92}{200 R_{g}} \cdot\left(\frac{200}{T}-1\right)+\frac{2.8135}{R_{g}} \ln \left(\frac{T}{200}\right)\right]\right\}$

$h_{\mathrm{fg}}=1274.462-2.8135(\mathrm{~T}-273)$

$\sigma_{\infty}=26.1-0.231(\mathrm{~T}-273)$

where $\mathrm{T}$ is in $[\mathrm{K}]$.

\section{REFERENCES:}

1. Farkas, L., Z. Physik, Chem. (Leipzig), Vol. 125, p.236, 1927.

2. Volmer, M. and Flood, H., Z. Physik. Chem., A170, 273, 1934.

3. Barschdorff, D., Hausmann, G. and Ludwig, A., "Flow and drop size investigations of wet steam at sub-and supersonic velocities with the theory of homogeneous condensation", Pr. Inst. Maszyn rzeplywowych, Zeszyt 70-72, pp.241-256, 1976.

4. Feder, J., Russell, K.C., Lothe, J. and Pound, G.M., "Homogeneous nucleation and growth of droplets in vapours", Adv. Phys., Vol.15, pp.111-118, 1966.

5.Gyarmathy, G. and Lesch, F., "Fog droplet observation in Lavel nozzles and in an experimental turbine", Proc. Inst. Mech. Eng. (London), Vol.184, Part 3G(III), pp.29-36, 1969-1970.

6. Petr, V., "Measurement of an average size and number of droplets during spontaneous condensation of supersaturated steam", Proc. 
Inst. Mech. Eng. (London), Vol. 184, Part 36(III), pp.22-28, 19691970.

7. Jaeger, H.L., Wilson, E.J., Hill, P.G. and Russell, K.C., "Nucleation of supersaturated vapours in nozzles. $\mathrm{I} . \mathrm{H}_{2} \mathrm{O}$ and $\mathrm{NH}_{3}$ ", J. Chem. Phys., Vol. 51, No.12, pp.5380-5388, 1969.

8. Duff, K.M. and Hill, P.G., "Condensation of carbon dioxide in supersonic nozzles", Proc. 1966 Heat Transfer and Fluid Mech. Inst., Edited by: Saad, M.A. and Miller, J.A., Stanford Univ. Press, Stanford, California, p. 262, 1966.

9. Dawson, D.B., "Condensation of supersaturated vapours in a supersonic nozzle", Master Thesis, Mass. Inst. of Tech., Cambridge, Massachusetts, 1967.

10. Saltanov, G.A., Seleznev, L.I. and Tsiklauri, G.V., "Generation and growth of condensed phase in high-velocity flows", Int. J. Heat Mass Transfer, Vol.16, pp.1577-1587, 1973.

11. Moore, M.J., Walters, P.T., Crane, R.I. and Davidson, B.J., "Predicting the fog-drop size in wet steam turbines", Inst. Mech. Engrs., Wet Steam 4, Paper C37/73 conference, Univ. of Warwick, April 1973.

12. Bakhtar, F., Ryley, D.J., Tubman, K.A. and Young, J.B., "Nucleation studies in flowing high pressure steam", Proc. Inst. Mech. Engrs., Vol. 189, pp. 427-436, 1975.

13. Gyarmathy, G., "Bases for a theory for wet steam turbines", Bull.6 Inst. for Thermal Turbomachines, Federal Technical University, Zurich, 1964.

14. Singh, U.K., "Method for nucleating steam flow in low-pressure turbine stages", Inst. Mech. Engrs., paper C557/010/99, pp.827836, London, 1999.

15. Hill, P.G., "Condensation of water vapour during supersonic expansion in nozzles", J. Fluid Mech., Vol.25, Part 3, pp.593-620, 1966.

16. Wegener, P.P. (Editor), “Nonequilibrium flows”, Part I, Marcel Dekker, New York, 1969.

17. Kantrowitz, A., "Nucleation in very rapid vapour expansions", J. Chem. Phys., Vol.19, pp.1097-1102, 1951.

18. Young, J.B., "The spontaneous condensation of steam in supersonic nozzles", Physico Chemical Hydrodynamics, Vol.3, No.1, pp.57-82. 1982.

19. Wegener, P.P., Clumpner, J.A. and Wu, B.J.C., "Homogeneous nucleation and growth of ethanol drops in supersonic flow", Phys. Fluids, Vol.15, No.11, pp.1869-1876, 1972. 


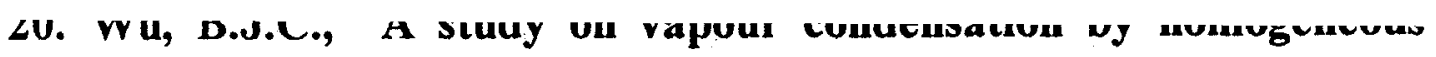
nucleation in nozzles", Ph.D. Thesis, Yale University, 1972.

21. Moore, M.J. and Sieverding, C.H. (Eds.), "Two-phase steam flow in trubines and separators", Hemisphere Publ. Cor., Washington, 1976.

22. Young, J.B., "Wet steam flows", Cambridge University lecture series on turbomachinery, Cambridge, UK, 1994.

23. Cinar, G., Yilbas, B.S. and Sunar, M., "Study into nucleation of steam during expansion through a nozzle", Int. J. Multiphase Flow, Vol.23, No.6, pp.1171-1188, 1997.

24. Douglas, J.F., Gasiorek, J.M. and Swaffield, J.A., "Fluid Mechanics", ELBS and Pitman Publ., London, UK, 1981.

25. Perry, J.H., "Perry's chemical engineers' handbook", McGrawHill Book Comp., New York, Sixth, Ed., 1984.

26. Barschdorff, D., "Verlauf der Zustandsgro $\beta$ en und gasdynamische Zusammenhange bei der spontanen kondensation reinen wasserd-ampfes in Lavaldusen", Forschung Ing., Wes. 37, pp. 146-157, 1971.

27. Wegener, P.P. and Pouring, A.A., "Experiments on condensation of water vapour by homogeneous nucleation in nozzles", Phys. Fluids, Vol.7, pp. 352-359, 1964.

28. Tolman, R.C., "The effect of droplet size on surface tension", J. Chem. Phys., Vol. 17, No.3, pp.333-337, 1949.

29. Dawson, D.B., Willson, E.J., Hill, P.G. and Russell, K.C., "Nucleation of supersaturated vapours in nozzles. II. $\mathrm{C}_{6} \mathrm{H}_{6}, \mathrm{CHCl}_{3}$, $\mathrm{CCl}_{3} \mathrm{~F}$, and $\mathrm{C}_{2} \mathrm{H}_{5} \mathrm{OH}^{\prime \prime}$, J. Chem. Phys., Vol. 51, No.12, pp. 5389$5397,1969$. 

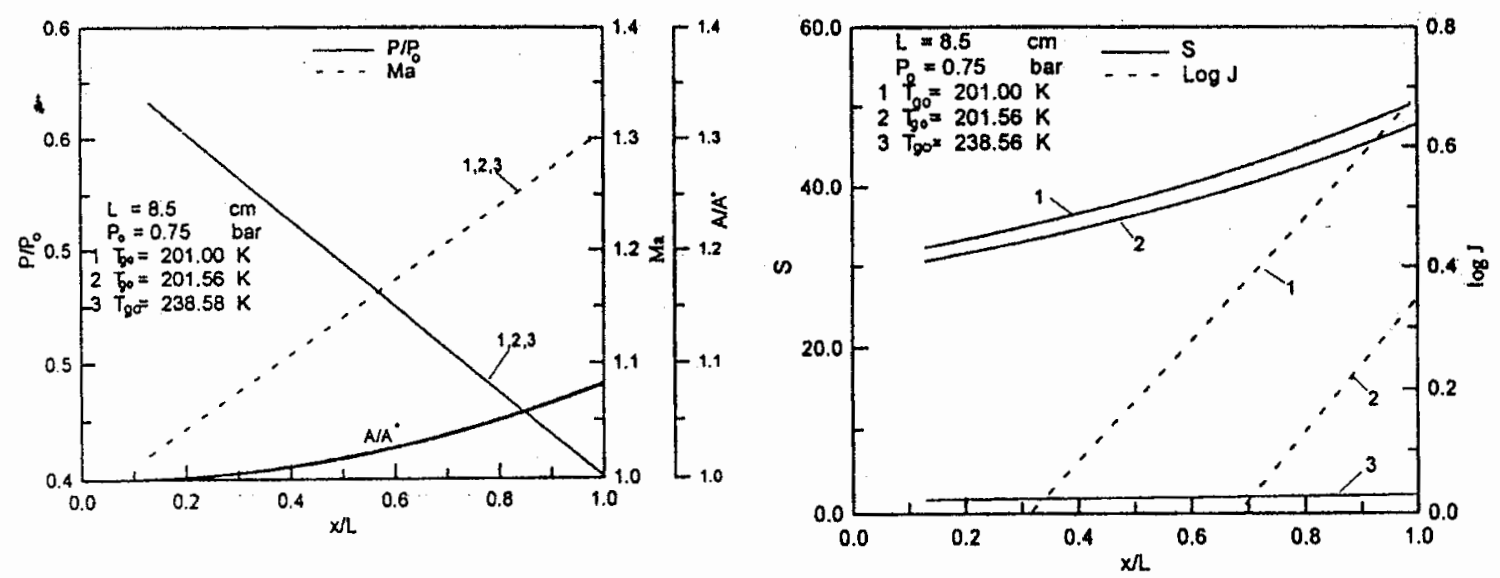

(a)

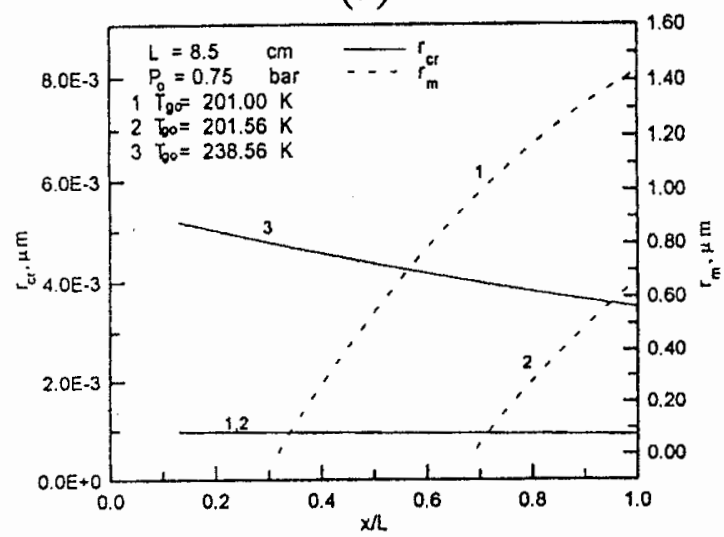

(c) (b)

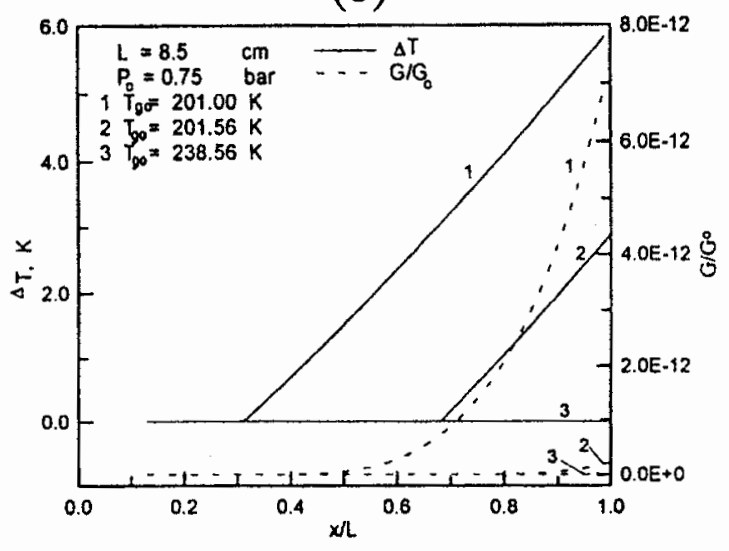

(d)

Figure 1 Variation of the flow and condensation characteristics, during Freon -11 expansion in nozzle (1), with the inlet flow temperature $(\mu=0.1)$. 


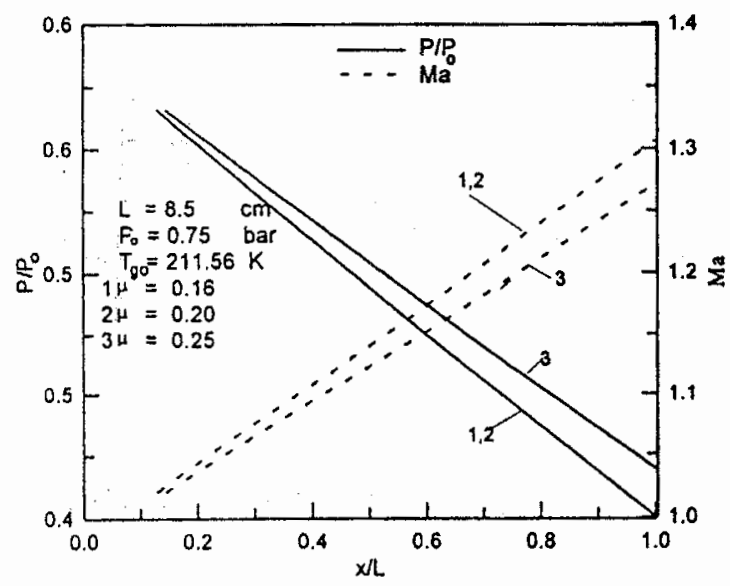

(a)

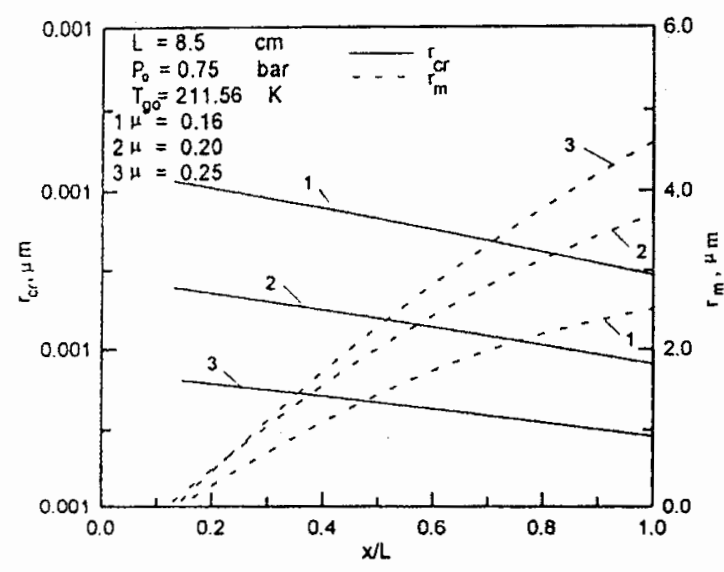

(c)

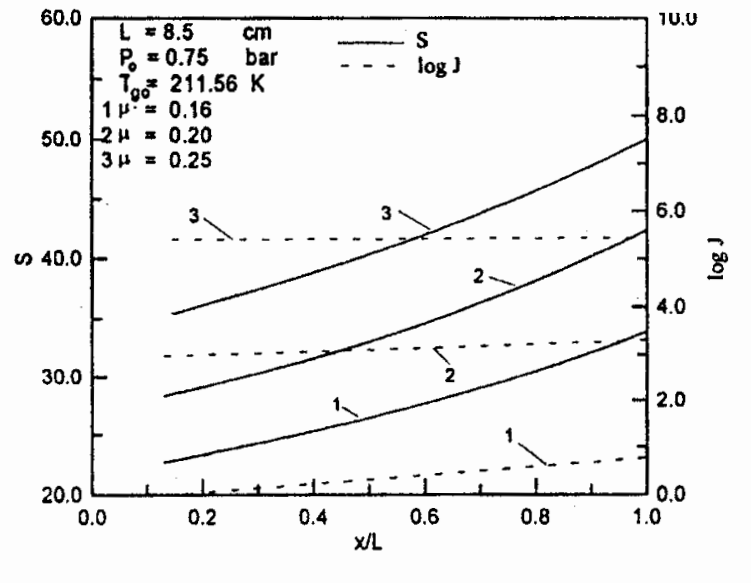

(b)

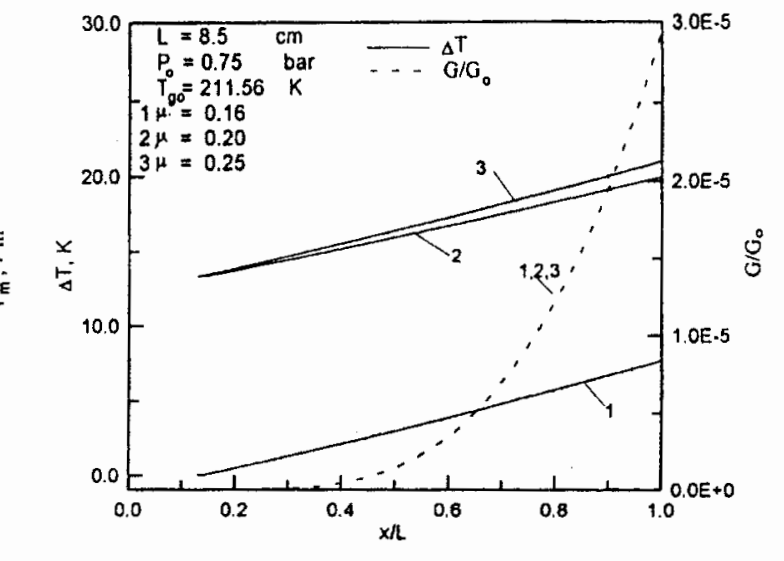

(d)

Figure 2 Variation of the flow condensation characteristics with the initial mass fraction of Freon -11, during its expansion in the nozzle (1). 


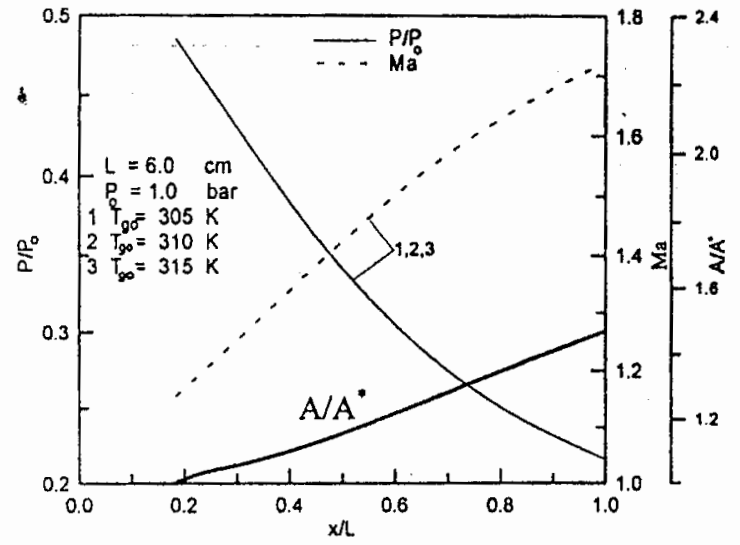

(a)

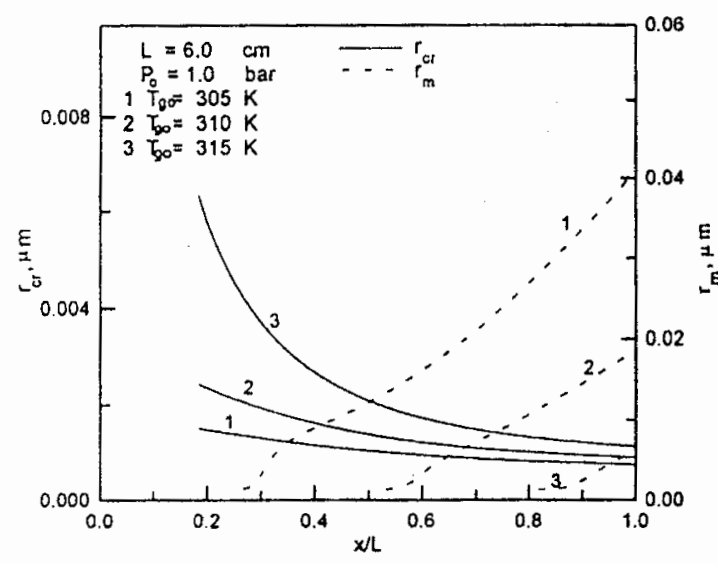

(c)

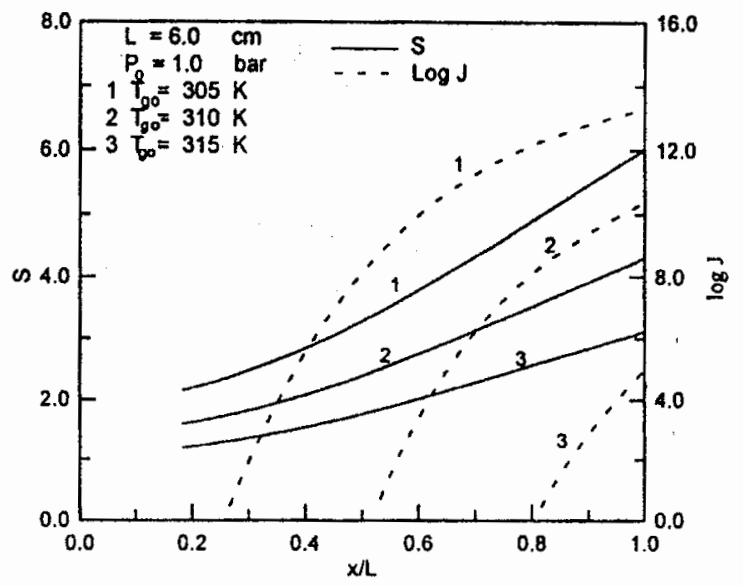

(b)

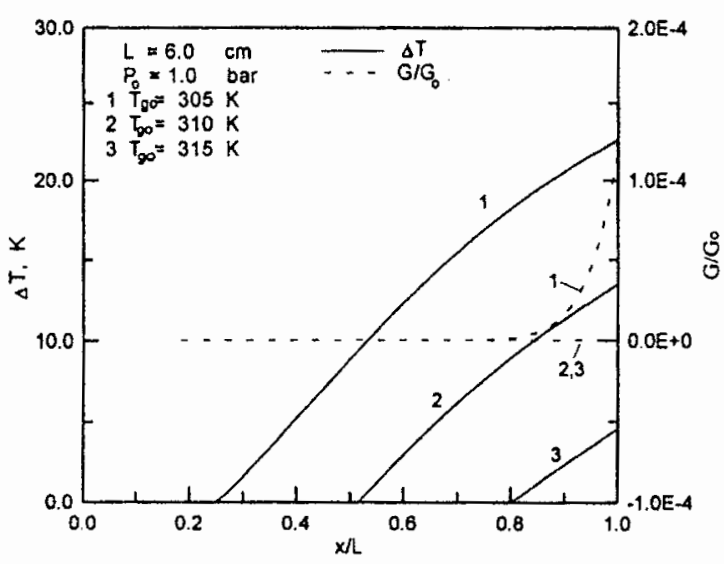

(d)

Figure 3 Summary of the changes of the flow and condensation characteristics with the inlet flow temperature during Ethanol condensation along nozzle (2). 


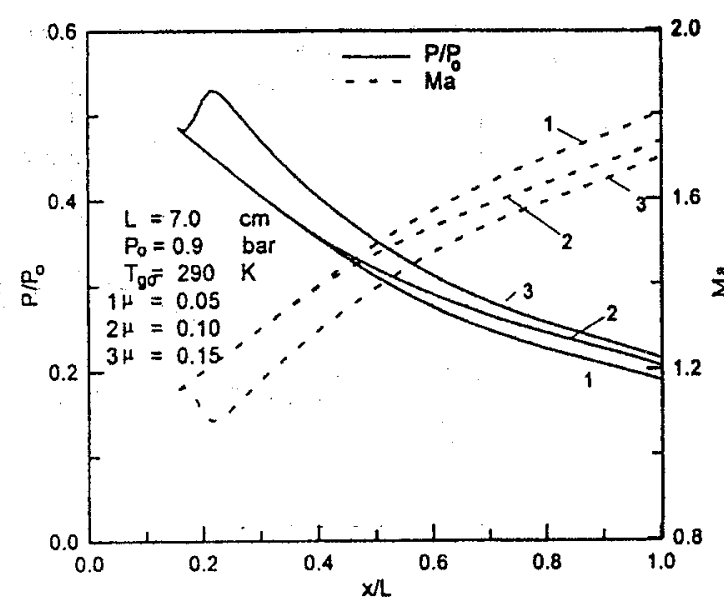

(a)

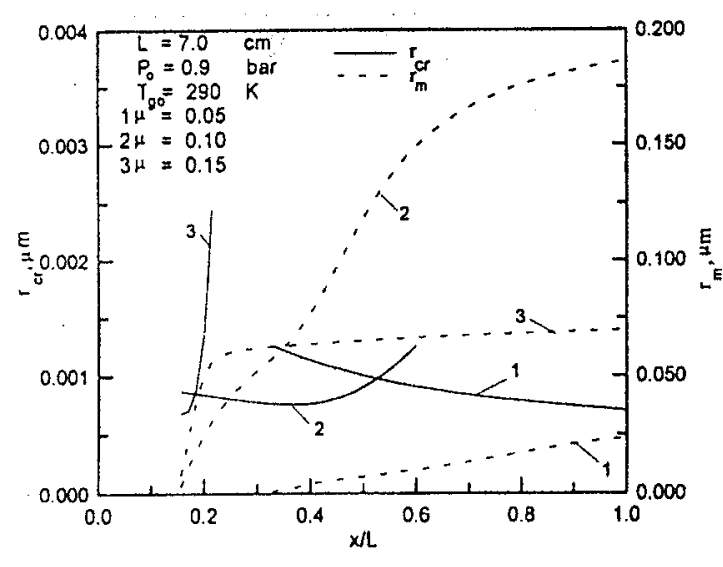

(c)

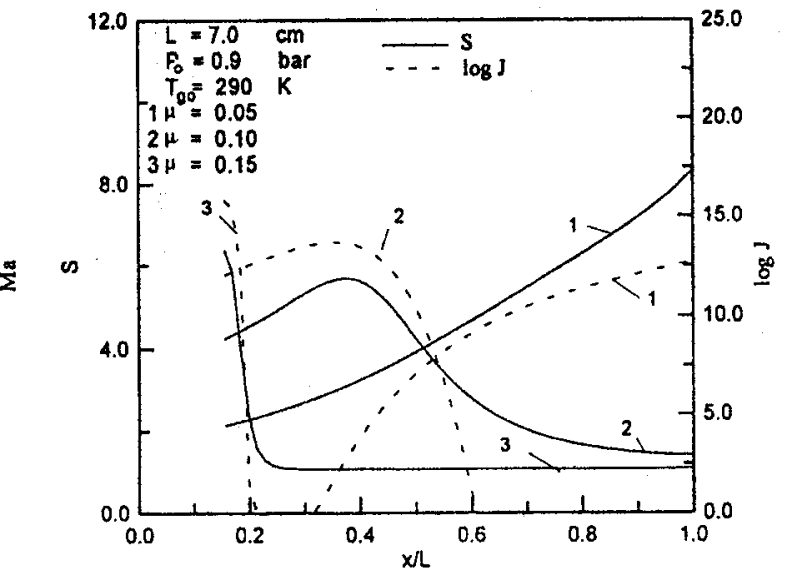

(b)

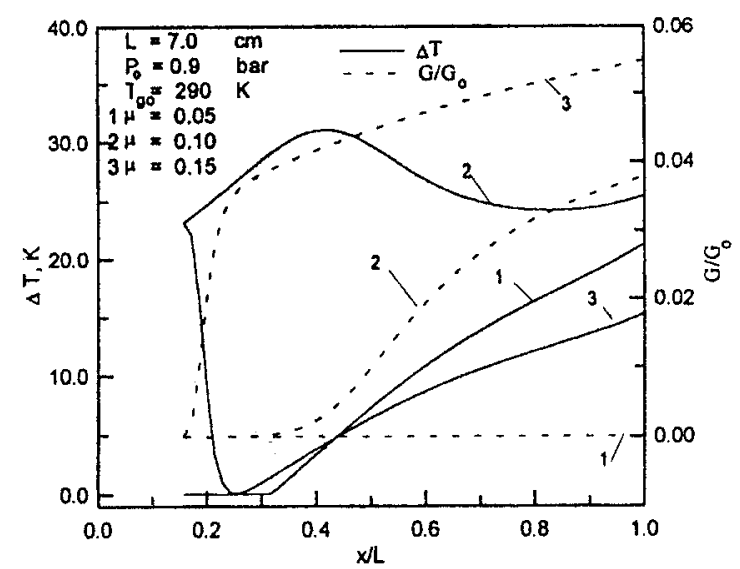

(d)

Figure 4 Summary of the changes in the flow and condensation characteristics with the initial mass fraction of Ethanol during its expansion in along nozzle (2). 


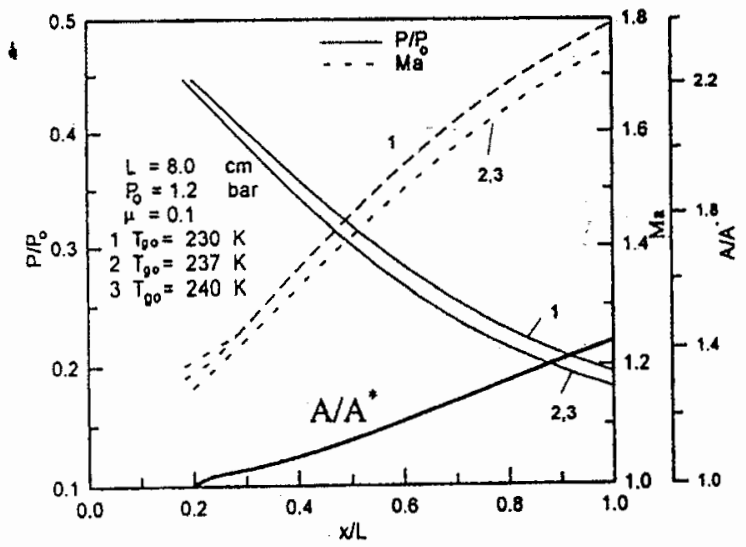

(a)

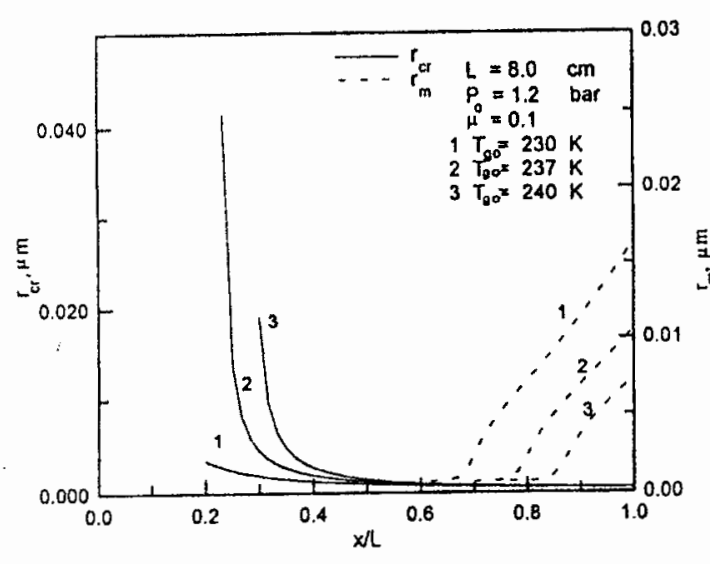

(c)

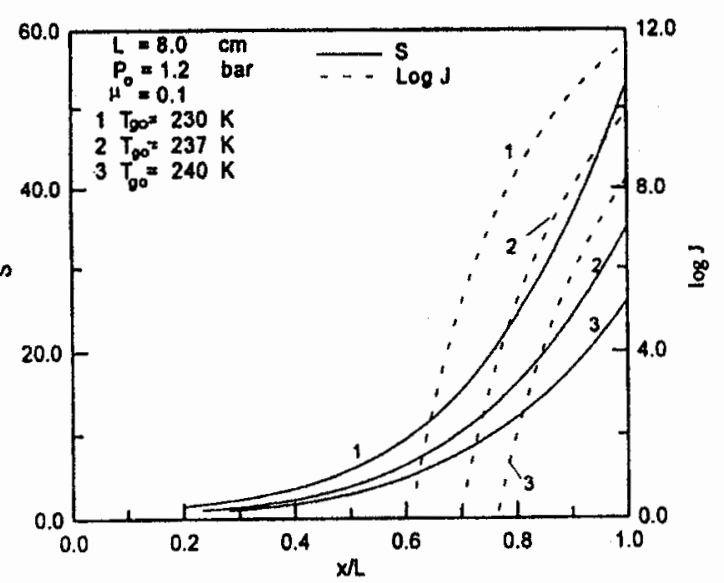

(b)

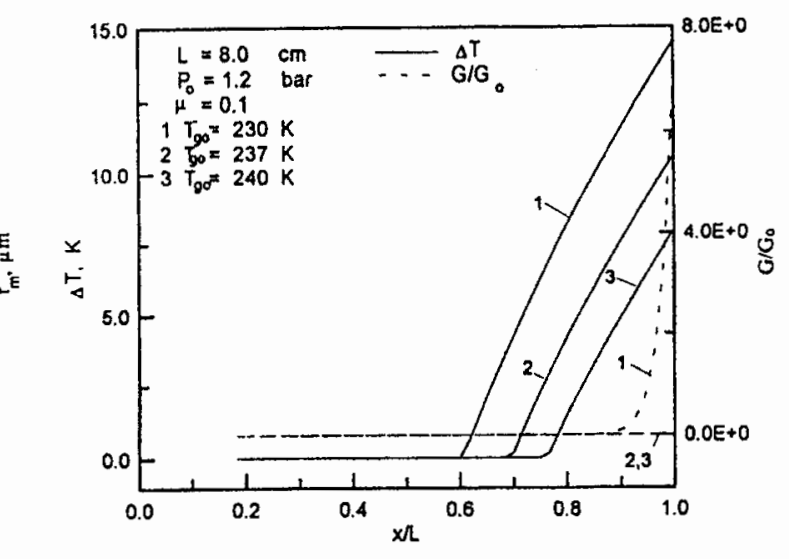

(d)

Figure 5 Effect of the inlet flow temperature on the predicted flow and condensation characteristics of Ammonia expansion in nozzle (2) 


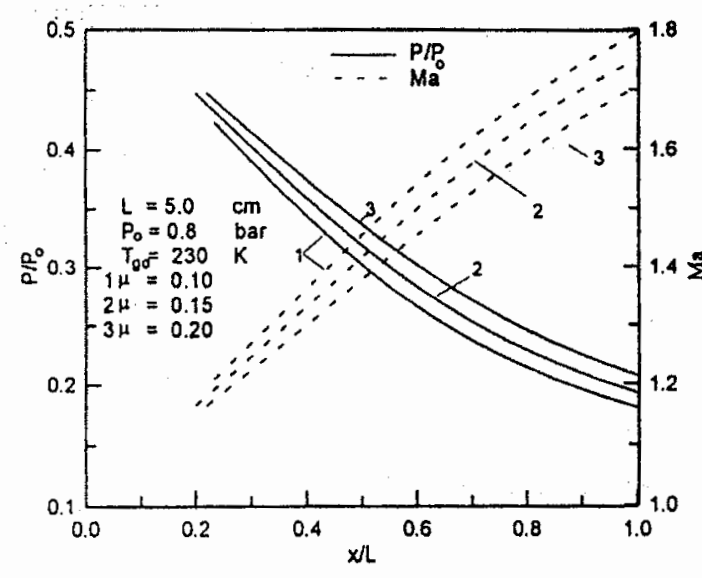

(a)

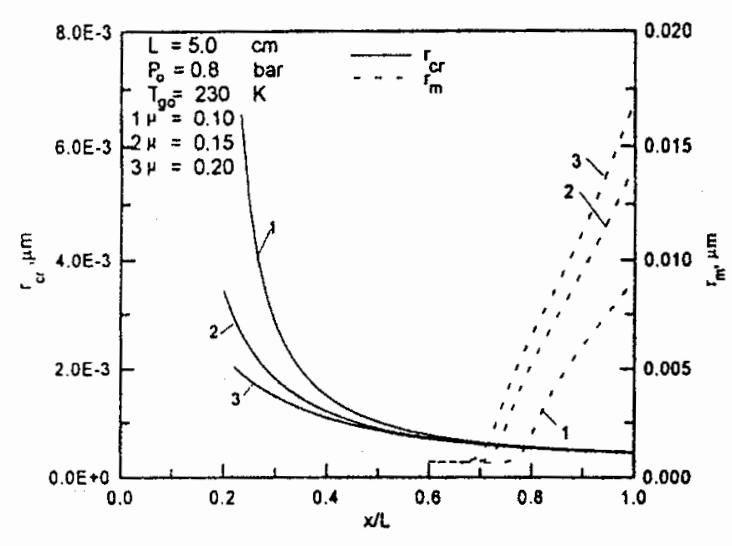

(c)

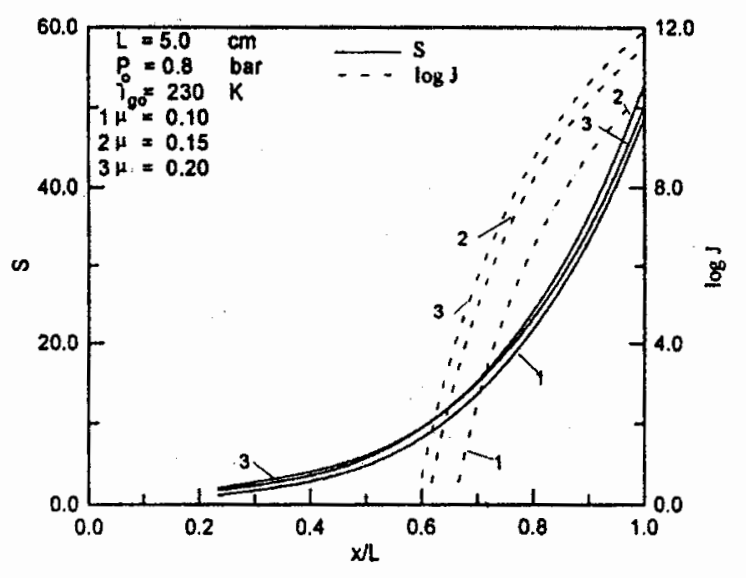

(b)

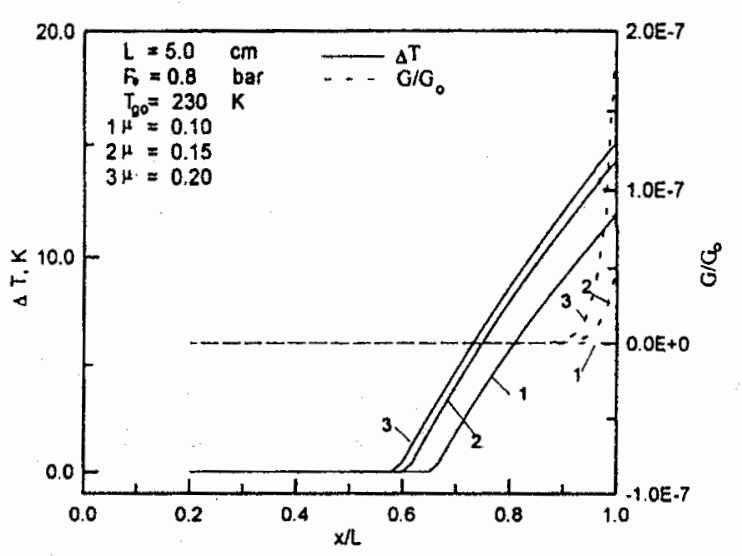

(d)

Figure 6 Effect of the initial mass fraction of Ammonia on the predicted flow and condensation characteristics through nozzle (2) 


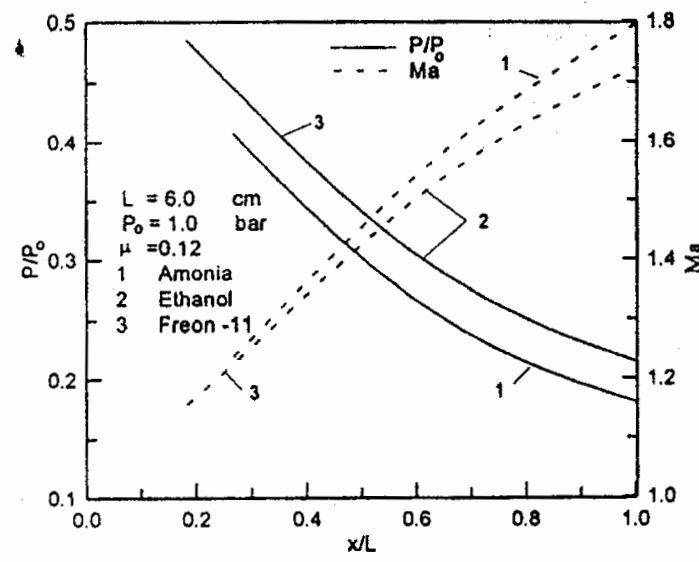

(a)

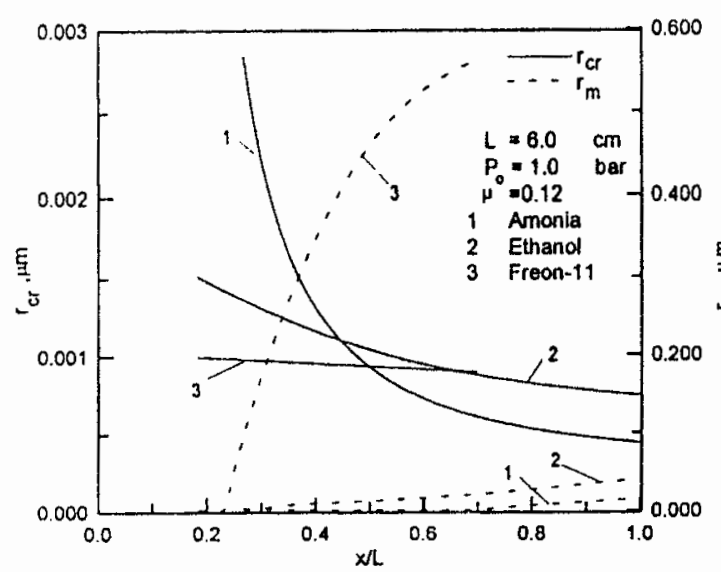

(c)

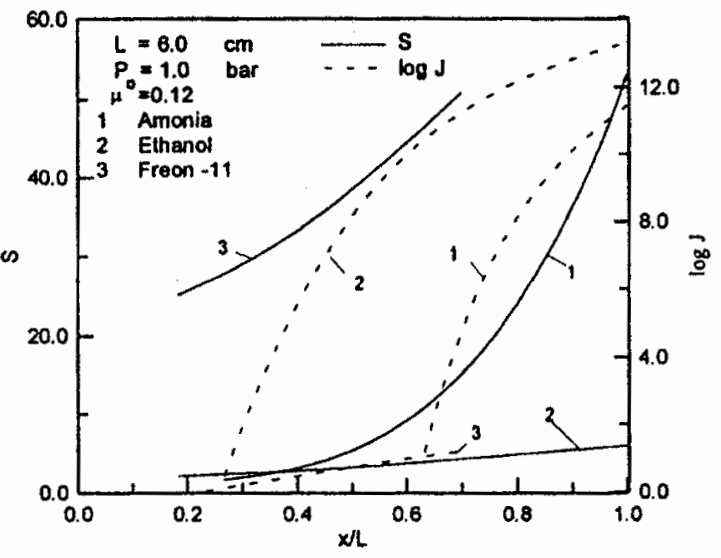

(b)

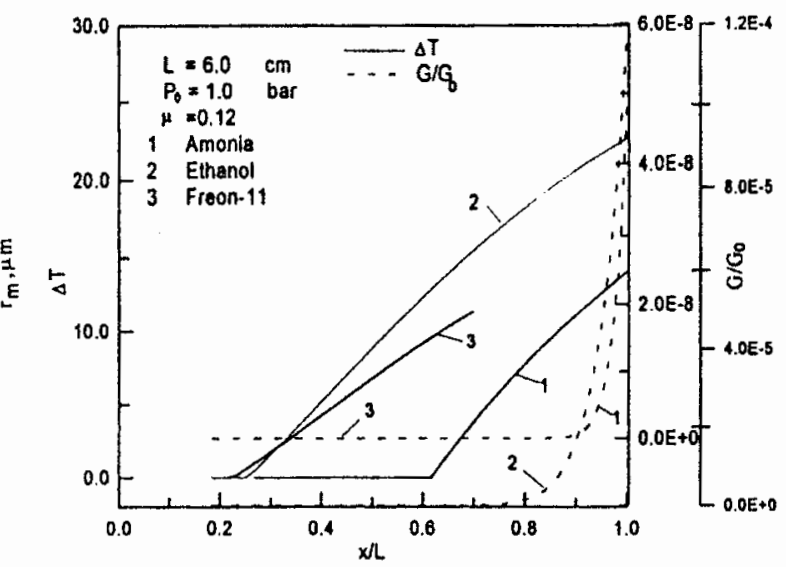

(d)

Figure $7 \mathrm{~A}$ comparison between the flow and condensation characteristics of the tested organic vapours during expansion in nozzle (2). 


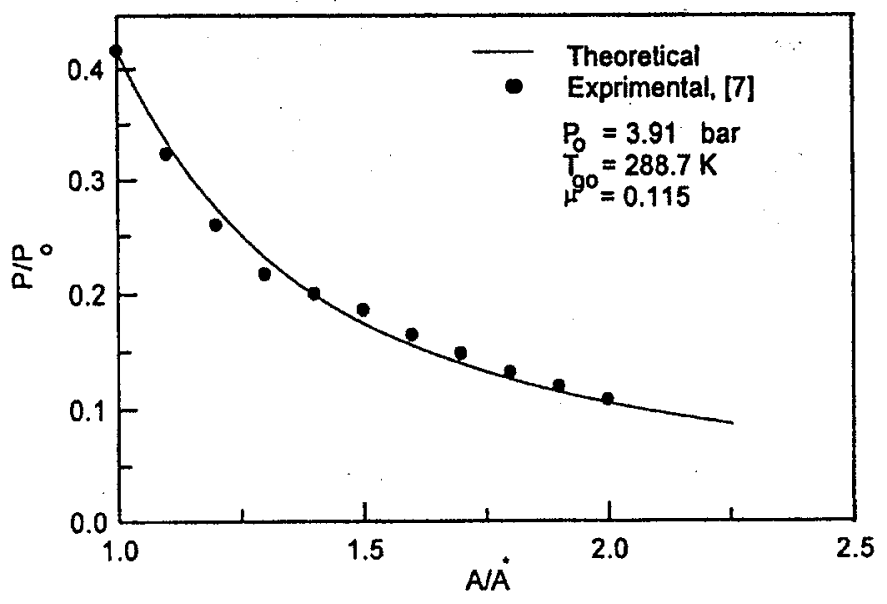

(a)

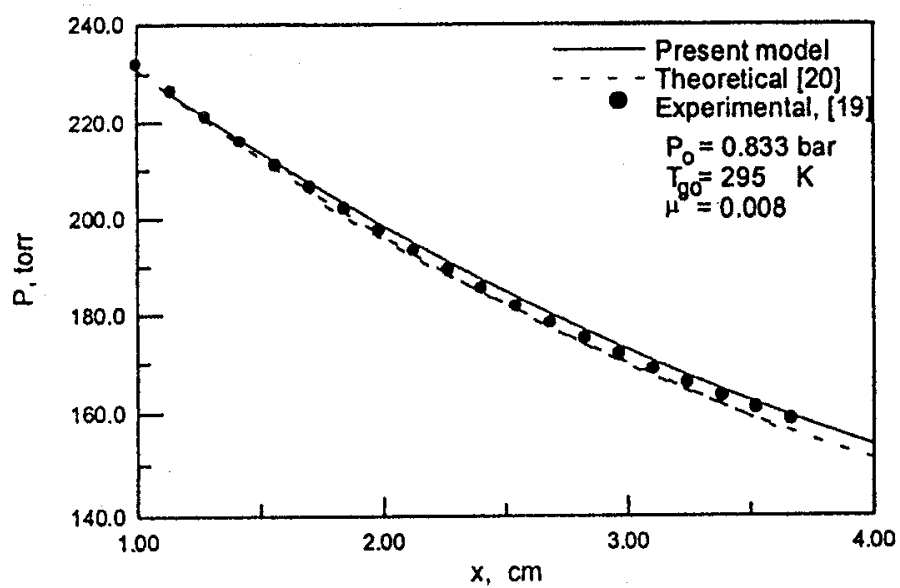

(b)

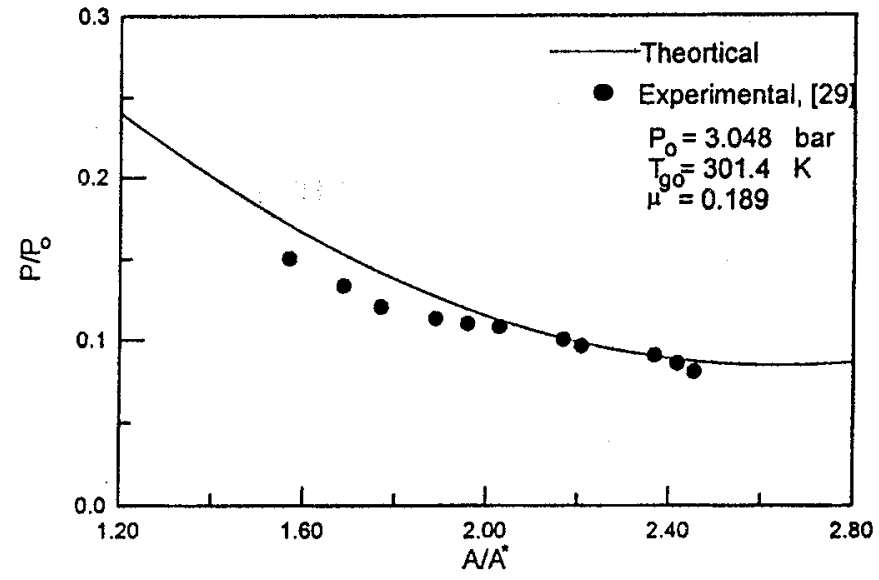

(c)

Figure 8 Comparison between the predicted and measured pressure distribution during supersonic expansions in nozzles for: a- Ammonia, b-Ethanol and c- Freon - 11 . 


\section{الخصائص المميزة للتكثف أثثاء الإنسياب فوق الصونى للأبخرة العضوية}

$$
\text { نبيل حنفى محمود }
$$

قسم هندسة القوى المبكانيكية - جامعة المنوفيه

\section{ملخص البحث:}

تهتم هذه الورقة بلراسة تكثف بعض الأبخرة العضوية كالأمونيا - الإيثانول وفريون-11 بالنمط

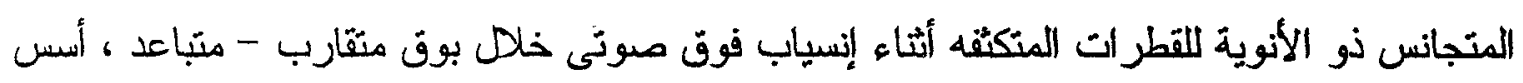
النموذج النظرى المقدم فى هذه الورقة على ثلاثت مجموعات من المعادلات نسمى: معادلات ديناميكا

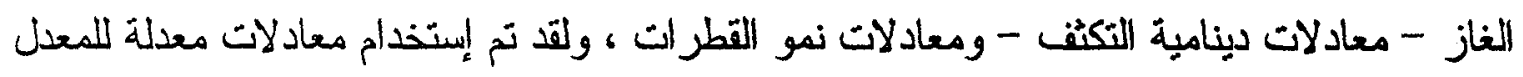
الكلاسيكى لتولد القطرات - الشد السطحى على سطح القطرات - ـ الخواص الثرموديناميكية للبخار

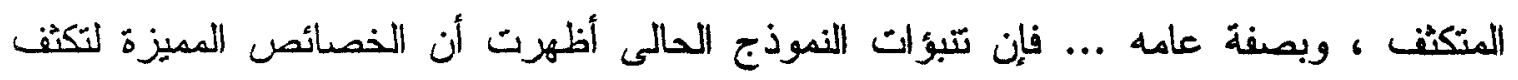

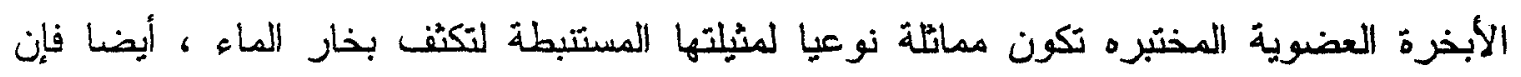

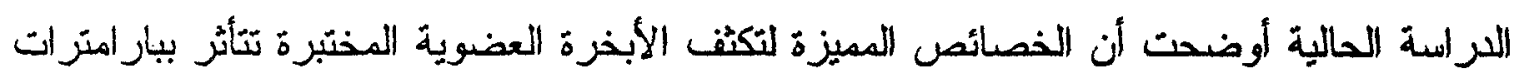

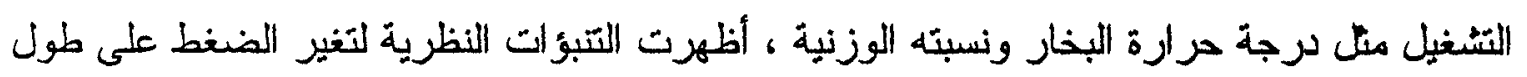
الجزء المنباعد فى أبواق فوق صوتية تو اققا جيدا مع القياسات المعملية المنتورة لهذه الأبخرة. 